\title{
The molecular mechanisms of signaling by cooperative assembly formation in innate immunity pathways
}

Parimala R. Vajjhala ${ }^{\mathrm{a}}$, Thomas Ve ${ }^{\mathrm{a}, \mathrm{b}}$, Adam Bentham ${ }^{\mathrm{a}, \mathrm{c}}$, Katryn J. Stacey ${ }^{\mathrm{a}}$ and Bostjan Kobe ${ }^{\mathrm{a}, *}$

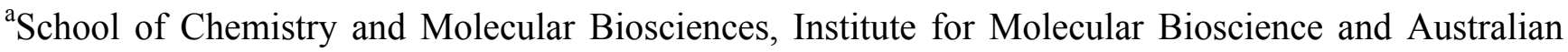

Infectious Diseases Research Centre, University of Queensland, Brisbane, QLD 4072, Australia.

${ }^{\mathrm{b}}$ Institute for Glycomics, Griffith University, Southport, QLD 4222, Australia

${ }^{\mathrm{c}}$ School of Biological Sciences, Flinders University, Adelaide, SA 5001, Australia

*Corresponding author: Bostjan Kobe, (b.kobe@uq.edu.au)

\section{Highlights}

-Pattern recognition receptors (PRRs) of the mammalian innate immune system mediate the first line of defense against pathogens and danger signals

-PRRs signal via oligomeric signaling complexes that assemble via co-operative assembly mechanisms -Signaling by co-operative assembly formation (SCAF) allows PRRs to respond rapidly and amplify the response to a low level of stimulus

- The molecular mechanisms of SCAF by NLR, PYHIN family, TLR and RIG-I receptors are reviewed -Conservation of SCAF in plants and fungi is discussed

\section{Keywords}

higher-order assembly signaling, inflammasome, nucleotide binding and oligomerization domain, leucine-rich repeat-containing/nucleotide and oligomerization domain-like receptor (NLR), RIG-1-like receptor (RLR), signaling by co-operative assembly formation (SCAF), Toll-like receptor (TLR)

\begin{abstract}
Abbreviations
CARD, caspase recruitment domain; CC, coiled-coil; DAMP, danger-associated molecular pattern; DD, death domain; DED, death effector domain; NBD, nucleotide-binding domain; NLR, nucleotide binding and oligomerization domain (NOD), leucine-rich repeat (LRR)-containing/nucleotide and oligomerization domain-like receptor; OB, oligonucleotide/oligosaccharide binding; PAMP, pathogenassociated molecular pattern; PRR, pattern recognition receptors; PYD, pyrin domain; RLR, RIG-1-
\end{abstract}


like receptor; SCAF, signaling by co-operative assembly formation; TIR domain, Toll/interleukin-1 receptor domain; TLR, Toll-like receptor 


\begin{abstract}
The innate immune system is the first line of defense against infection and responses are initiated by pattern recognition receptors (PRRs) that detect pathogen-associated molecular patterns (PAMPs). PRRs also detect endogenous danger-associated molecular patterns (DAMPs) that are released by damaged or dying cells. The major PRRs include the Toll-like receptor (TLR) family members, the nucleotide binding and oligomerization domain, leucine-rich repeat containing (NLR) family, the PYHIN (ALR) family, the RIG-1-like receptors (RLRs), C-type lectin receptors (CLRs) and the oligoadenylate synthase (OAS)-like receptors and the related protein cyclic GMP-AMP synthase (cGAS). The different PRRs activate specific signaling pathways to collectively elicit responses including the induction of cytokine expression, processing of pro-inflammatory cytokines and celldeath responses. These responses control a pathogenic infection, initiate tissue repair and stimulate the adaptive immune system. A central theme of many innate immune signaling pathways is the clustering of activated PRRs followed by sequential recruitment and oligomerization of adaptors and downstream effector enzymes, to form higher-order arrangements that amplify the response and provide a scaffold for proximity-induced activation of the effector enzymes. Underlying the formation of these complexes are co-operative assembly mechanisms, whereby association of preceding components increases the affinity for downstream components. This ensures a rapid immune response to a low-level stimulus. Structural and biochemical studies have given key insights into the assembly of these complexes. Here we review the current understanding of assembly of immune signaling complexes, including inflammasomes initiated by NLR and PYHIN receptors, the myddosomes initiated by TLRs, and the MAVS CARD filament initiated by RIG-1. We highlight the co-operative assembly mechanisms during assembly of each of these complexes.
\end{abstract}




\section{Contents}

1. Introduction

2. Co-operative assembly formation in the inflammasome signaling pathway

2.1 The inflammasome is a filamentous network

2.2 Inflammasome-initiating PRRs oligomerize via co-operative assembly mechanisms

2.2.1 The PYHIN family member AIM2

2.2.1.1 Oligomerization of the AIM2 HIN domain on dSDNA

2.2.1.2 Clustering of the AIM2 PYD upon AIM2 oligomerization on DNA

2.2.1.3 Oligomerization of AIM2 on $d s D N A$ involves multiple steps of co-operative assembly

2.2.2 The NLR family

2.2.2.1 Activation of NAIP2 and oligomerization with NLRC4 via the NOD

2.2.2.2 Oligomerization of the NAIP2/NLRC4 complex is a co-operative assembly process

2.2.2.3 Clustering of the NLRC4 CARDs in the NAIP2/NLRC4 oligomer

2.3 The inflammasome adaptor ASC amplifies the signal and bridges the interaction of PRRs with effector caspases

2.3.1 Nucleation of ASC PYD filaments by PYD-containing PRRs

2.3.2 Nucleation of ASC PYD filaments by the NAIP/NLRC4 oligomer

2.3.3 Condensation of ASC filaments by ASC CARD interactions to form a compact speck

2.3.4 Nucleation of procaspase-1 CARD filaments by ASC CARDs

2.3.5 Nucleation of procaspase-1 CARD filaments by NLRC4 CARDs of the NAIP/NLRC4 oligomer

2.3.6 Nucleation of procaspase-8 DED filaments by ASC PYD

3. Co-operative assembly formation in the RLR and TLR signaling pathways

3.1 The RLR family

3.1.1 Receptor oligomerization

3.1.2 MAVS filament formation

3.2 The TLR family

3.2.1 Receptor dimerization triggers MyD88 and TRIF oligomerization

3.2.2 The TIR domain signalosome

4. Conservation of SCAF in plants and fungi

4.1 NLRs in other kingdoms of life 
4.2 Plant NLRs

4.3 Fungal NLRs

5. Conclusions 


\section{Introduction}

The innate immune system has evolved a number of pattern recognition receptors (PRRs) that sense the presence of pathogens via recognition of conserved pathogen-associated molecular patterns (PAMPs). PRRs also respond to endogenous molecules released from damaged or dying cells, which are referred to as danger-associated molecular patterns (DAMPs). Major families of PRRs include the nucleotide binding and oligomerization domain, leucine-rich repeat (LRR) containing (NLR) family (also referred to as the nucleotide binding and oligomerization domain (NOD)-like receptor family), the Toll-like receptor (TLR) family of transmembrane receptors, the PYHIN (pyrin and HIN200 domain-containing) family, the RIG-I-like receptor (RLR) family, the C-type lectin receptors (CLRs) and oligoadenylate synthase (OAS) proteins and the related protein cyclic GMP-AMP (cGAMP) synthase (cGAS). Upon activation, these PRRs initiate signaling pathways to induce immediate host defense mechanisms and also promote the adaptive immune response (Pandey et al., 2015).

Signaling via assembly of multi-protein complexes that enable proximity-induced activation of effector enzymes has emerged as a mode of signaling by many PRRs (Hauenstein et al., 2015; Lu and Wu, 2015; Wu, 2013; Yin et al., 2015). Activated PRRs cluster to recruit and nucleate the oligomerization of adaptor proteins, which in turn recruit and nucleate oligomerization of effector enzymes. Recent structural and biochemical studies of PRRs and components of their signaling complexes have revealed co-operative assembly mechanisms during their oligomerization (Lin et al., 2010; Lu et al., 2016; Lu et al., 2014b; Xu et al., 2014). In most cases, oligomerization of preceding components presents multiple interaction sites to downstream proteins to mediate co-operative assembly. Cooperative assembly can also be mediated by induction of a conformational change in a protein that facilitates interaction with downstream components. We refer to this mode of signaling as "signaling via co-operative assembly formation" (SCAF). SCAF provides a scaffold for proximity-induced activation of downstream effector enzymes and also enables PRRs to respond rapidly to low levels of DAMPs and PAMPs. Here we highlight the mechanism of SCAF as revealed from structures of components of the inflammasome initiated by NLR and PYHIN proteins, the MAVS CARD filament initiated by RIG-I, and the myddosome initiated by TLR4.

\section{Co-operative assembly formation in the inflammasome signaling pathway}

\subsection{The inflammasome is a filamentous network}

Inflammasomes are cytosolic signaling complexes that were originally shown to recruit and activate procaspase-1, which processes the proinflammatory cytokines, interleukin-1 $\beta$ (IL-1 $\beta$ ) and IL-18, and also cleaves gasdermin D to mediate pyroptotic cell death (Martinon et al., 2002; Rathinam and Fitzgerald, 2016; Shi et al., 2015). However, more recent studies have shown that inflammasomes also recruit and activate procaspase- 8 to mediate apoptotic cell death and pro-IL- $1 \beta$ processing (Antonopoulos et al., 2015; Chung et al., 2016; Martin et al., 2016; Pierini et al., 2012; Sagulenko et al., 2013). Deregulated inflammasome activation contributes to the pathology of many common diseases (Guo et al., 2015) and thus all aspects of inflammasome biology, including its activation and mechanism of assembly, are of interest. Canonical inflammasomes generally consist of a PRR, the adaptor protein ASC (apoptosis-associated speck-like protein containing a caspase recruitment 
domain) and the downstream effectors enzymes caspases-1 and -8. Notably, most components of inflammasomes have death-fold domains, which generally interact homotypically to form helical filaments using conserved interaction modes (Hauenstein et al., 2015; Kersse et al., 2011; Lu and Wu, 2015). Inflammasome assembly (Fig. 1) involves ligand-induced activation and oligomerization of the PRR, which subsequently nucleates filaments of the adaptor ASC, a major component of inflammasomes (Fernandes-Alnemri et al., 2007; Lu et al., 2014b). ASC filaments in turn nucleate filaments of procaspases-1 and -8 ( $\mathrm{Lu}$ et al., 2016; Lu et al., 2014b; Vajjhala et al., 2015). The filamentous nature of the inflammasome is visible by electron microscopy of isolated inflammasomes (Franklin et al., 2014). Assembly into filaments amplifies the response (Dick et al., 2016) and provides a scaffold for the proximity-induced activation of the caspases. The entire cascade of events involves multiple steps of co-operative assembly. We review the mechanisms of activation of the AIM2 and NAIP2/NLRC4 inflammasomes, which are currently the best-characterized structurally, and highlight the mechanisms of co-operative assembly.

\subsection{Inflammasome-initiating PRRs oligomerize via co-operative assembly mechanisms}

Inflammasomes are initiated upon activation of structurally diverse PRRs including certain NLR family members, the PYHIN family protein AIM2, and the TRIM family protein pyrin (Rathinam and Fitzgerald, 2016). Although the structures of these protein families are quite diverse, they all have a domain that mediates the oligomerization of the PRR. In the NLR family proteins, the NOD mediates oligomerization (Hu et al., 2015; Zhang et al., 2015), while the PYHIN protein AIM2 has a HIN domain that binds to and oligomerizes along double-stranded (ds) DNA ( $\mathrm{Lu}$ et al., 2015; Morrone et al., 2015). The pyrin inflammasome is less well-characterized, however, a coiled-coil (CC) domain is proposed to mediate its oligomerization ( $\mathrm{Yu}$ et al., 2006). Another common feature of most inflammasome-initiating PRR complexes is the presence of a death-fold domain, either a pyrin domain (PYD) or a caspase recruitment domain (CARD) (Sharma and Kanneganti, 2016).

\subsubsection{The PYHIN family member AIM2}

The PYHIN family proteins all have an N-terminal PYD-type death-fold domain and one or two copies of a HIN domain, each of which consists of two oligonucleotide/oligosaccharide binding (OB) folds (Fig. 2A). Members of the human family include AIM2 (absent in melanoma), IFI16, IFIX and MNDA (Cridland et al., 2012). AIM2 is the only member with a well-characterized role in inflammasome activation. AIM2 has been proposed to be in an auto-inhibited state due to interaction between the PYD and HIN domains until it senses and binds to dsDNA via the HIN domain (Jin et al., 2013). However, more recent work disputes this auto-inhibitory mechanism (Morrone et al., 2015).

2.2.1.1 Oligomerization of the AIM2 HIN domain on dsDNA. Initial structural studies of the AIM2 HIN domain/dsDNA complex revealed the structure of the HIN domain and the molecular details of its interaction with DNA (Jin et al., 2012). The structure revealed that each HIN domain consists of two $\beta$-barrel sub-domains, each of which is characteristic of the OB fold (Arcus, 2002). The two OB folds are stacked one above the other along the DNA and both OB folds and the linker between them are involved in binding to both strands of the dsDNA (Fig. 2A). Basic residues in the concave surface formed by the HIN domain bind to the negatively charged DNA backbone. More recent EM studies 
showed that the AIM2 HIN domains oligomerize along the length of dsDNA (Lu et al., 2015; Morrone et al., 2015) Modeling of the dsDNA/HIN polymer (Lu et al., 2015) using the crystal structure of the HIN domain/dsDNA complex as a template yielded a helical model whereby each HIN domain occupies 4 base-pairs (bp) of DNA and is surrounded by six adjacent HIN domains (Lu et al., 2015).

2.2.1.2 Clustering of the AIM2 PYD upon AIM2 oligomerization on DNA. As the N-terminus of the HIN domain is oriented away from the DNA in the crystal structure, the PYDs are expected to extend from the side of the HIN domain/dsDNA filament. The AIM2 PYD, similar to other death-fold domains, consists of six $\alpha$-helices arranged in an anti-parallel arrangement (Fig. 2B) (Jin et al., 2013; Kersse et al., 2011). It has been shown to form helical filaments in vitro and the structure of the filament was proposed based on negative-stain EM and homology modeling, using the structure of the ASC PYD filament ( $\mathrm{Lu}$ et al., 2015) as a template (Morrone et al., 2015). This suggested that like many other death-fold domains, the AIM2 PYD filament assembly uses six surfaces, to mediate three modes of interaction referred to as type I, II and III (Kersse et al., 2011; Park et al., 2007).

In vivo, it is likely that when full-length AIM2 binds to DNA, the PYDs extending from the side of the dsDNA/HIN domain cluster and assemble into a short helical segment (Lu et al., 2015; Morrone et al., 2015) (Fig. 2C). The length of the linker between the HIN and PYD is 50 amino acids, and this restricts the number of PYDs able to contribute to this short filament, of currently undefined length.

2.2.1.3 Oligomerization of AIM2 on dsDNA involves multiple steps of co-operative assembly. Because each HIN domain contacts six adjacent HIN domains (Lu et al., 2015), its assembly into a filament on dsDNA is likely to be co-operative, as once it is initiated, subsequent AIM2 molecules can bind to the DNA as well as to multiple sites on the elongating HIN domain filament. This ensures a rapid response once the DNA is sensed. Furthermore, co-operative assembly allows compact packing of the HIN domains on DNA that may present an excess of possible binding sites, and consequently maximizes AIM2 PYD clustering, which is required for the recruitment of the adaptor protein ASC. In addition, the AIM2 PYD promotes binding of AIM2 to DNA, because full-length AIM2 binds dsDNA more efficiently than the HIN domain alone (Morrone et al., 2015). Although this appears to be in some contradiction to previous studies suggesting that AIM2 PYD-HIN interaction mutually inhibits binding of AIM2 HIN domain to DNA and clustering of the PYDs (Jin et al., 2013), it is possible that the PYD-HIN interaction keeps AIM2 in an auto-inhibited state, but that once the HIN domain binds to DNA, the PYDs cluster and stabilize the complex.

\subsubsection{The NLR family}

The central NOD of the NLRs comprises a nucleotide-binding domain (NBD), an adjacent helical domain (HD1) and a winged helical domain (WHD) (Fig. 3A). The NBD and HD1 are common to $\mathrm{AAA}+$ family ATPases while the WHD is unique to the signal transduction ATPases with numerous domains (STAND) subfamily to which the NLRs belong (Danot et al., 2009; Leipe et al., 2004). A second helical domain (HD2), which is also referred to as an arm domain, links the NOD to the Cterminal LRR domain (Fig. 3A). The NOD of NLRs is also referred to as a NACHT domain named after NAIP, CIITA, HET-E and TP-1 proteins (Koonin and Aravind, 2000). Three types of NLRs are 
associated with inflammasomes. NLRs with an N-terminal PYD are referred to as NLRP, NLRs with an N-terminal CARD are referred to as NLRC, and NLRs with an N-terminal BIR domain are referred to as NLRB or more commonly as NAIP (NLR family, apoptosis inhibitory protein) (Ting et al., 2008).

NLRP family members that are known to form inflammasomes include NLRP1 and 3. NLRP3 in particular has been shown to be activated by a wide range of stimuli, including ATP, potassium ionophores, and particulate material (Rathinam and Fitzgerald, 2016), and has been shown to be associated with the pathology of many common diseases. However, the precise mechanism of NLRP3 activation is not known. Although NLRP6, 7 and 12 are proposed to form inflammasomes, the evidence for these inflammasomes is less substantial. Negative-stain EM of NLRP1 has indicated the formation of an oligomeric ring (Faustin et al., 2007); however, there are no detailed structural studies of NLRP-type NLRs. NAIP and NLRC4 NLRs assemble together to initiate inflammasomes (Kofoed and Vance, 2011). The NAIPs are activated by ligand binding and then recruit NLRC4 to initiate inflammasome assembly. There is a single NAIP protein in humans and it is activated by flagellin (Kortmann et al., 2015) and by needle proteins of the type III secretion system (T3SS) (Yang et al., 2013), which transfers bacterial proteins into eukaryotic host cells. There are seven NAIP proteins in mouse. NAIP1 is suggested to function as the mouse homologue of human NAIP and is also activated by needle proteins of T3SS (Yang et al., 2013). Mouse NAIP2 recognizes the T3SS rod protein PrgJ while NAIP5 is activated by bacterial flagellin (Kofoed and Vance, 2011; Zhao et al., 2011). Recent structural studies have given key insights into the assembly of the NAIP2/NLRC4 and NAIP5/NLRC4 inflammasome initiator complexes (Diebolder et al., 2015; Hu et al., 2015; Zhang et al., 2015).

2.2.2.1 Activation of NAIP2 and oligomerization with NLRC4 via the NOD. The only high-resolution structure of an NLR monomer is that of NLRC4 without the CARD (Hu et al., 2013) and it revealed that the C-terminal LRR domain is bent over to contact the NBD and maintain it in an auto-inhibited state (Fig. 3B). In addition, WHD and HD2 also interact with the NBD to auto-inhibit it. Interestingly, the NBD-associated domains of NAIP2 and NAIP5, which include HD1, WHD and HD2, are the critical determinants for binding to PrgJ and flagellin (Tenthorey et al., 2014). The activated NAIPs then recruit NLRC4 molecules to form an inflammasome initiation platform (Kofoed and Vance, 2011; Zhao et al., 2011). As there is no evidence that NLRC4 senses the PAMP, it may be regarded as an adaptor (Hauenstein et al., 2015), while NAIPs are the PRRs. However, NAIPs cannot initiate inflammasome assembly in the absence of NLRC4. Thus the two together form an inflammasome initiation platform.

Cryo-EM analysis of complexes with PrgJ/NAIP2 and NLRC4 lacking the CARD (NLRC4 ${ }^{\mathrm{CARD}}$ ), indicated the formation of oligomeric rings with 10, 11 and 12-fold symmetry (Hu et al., 2015; Zhang et al., 2015). The NAIP and NLRC4 molecules were indistinguishable in these experiments due to their similar NOD and LRR domains. However, immunogold labeling indicated that each complex contained a single NAIP2 molecule (Hu et al., 2015). Furthermore, intermediates of the assembling ring could be detected by EM, consistent with sequential recruitment of NLRC4 molecules. Complexes with full-length NLRC4 formed double-ring structures, which are likely due to interactions mediated 
between the CARDs, and these mainly had 11 and 12-fold symmetry. In both reports (Hu et al., 2015; Zhang et al., 2015), a complex of NLRC4 ${ }^{\Delta \mathrm{CARD}}$ with 11 -fold symmetry was selected for detailed analysis and this was stated to be very similar to the complex with 11 -fold symmetry formed by fulllength NLRC4 (Hu et al., 2015) (Fig. 3C).

The interactions between the monomers in the ring are mediated by both the NOD and the LRR domain, which form an inner and outer ring, respectively. A basic patch formed by the NOD of one monomer interacts with an acidic patch formed by the NOD of an adjacent monomer and provides the major interaction that mediates oligomerization. The LRR domains also interact via complementary charged surfaces. Notably, the conformation of the NLRC4 monomer in the oligomeric ring differs from that of the inactive monomer by a rotation of $87.5^{\circ}$ in the HD1/WHD region that shifts the HD2/LRR away from the NBD (Hu et al., 2015; Zhang et al., 2015) (Fig. 3B).

Cryo-electron tomography of flagellin-induced NAIP5/full-length NLRC4 complexes (Diebolder et al., 2015) also revealed the formation of a double ring structure similar to that of the PrgJ-induced NAIP2/full-length NLRC4 complex. However, this study also identified a few helical polymers of NAIP5/NLRC4. While this is intriguing, it is unclear whether the helical polymers will form in cells expressing endogenous levels of protein. This study also noted a rotation of the LRR-HD2 domains away from the NBD of NLRC4 in the NAIP5/NLRC4 oligomer (Diebolder et al., 2015), compared to the NLRC4 monomer (Hu et al., 2013).

2.2.2.2 Oligomerization of the NAIP2/NLRC4 complex is a co-operative assembly process. In an inactive NLRC4 monomer, the acidic surface of the NOD is available for interaction, while the basic surface is sterically hindered by the LRR domain (Hu et al., 2015; Zhang et al., 2015). Although the structure of NAIP2 has not been solved, a homology model suggests it is likely to be similarly autoinhibited (Tenthorey et al., 2014). When NAIP2 interacts with PrgJ, it is proposed to undergo a conformational change that frees the basic surface formed by the NBD and WHD and allows interaction with the acidic surface formed by NBD, HD1 and WHD of an auto-inhibited NLRC4. Upon recruitment, the inactive NLRC4 is proposed to undergo a similar conformational change to the active conformation that allows it to use its basic surface on the NOD to recruit another NLRC4 molecule (Fig. 3D). This nucleated assembly is a co-operative mechanism, because the initial interaction of a NAIP/PrgJ complex with an NLRC4 molecule facilitates subsequent recruitment of NLRC4 molecules to form a ring. This mechanism allows a single PrgJ PAMP molecule to initiate an inflammasome and activate multiple effector caspases.

2.2.2.3 Clustering of the NLRC4 CARDs in the NAIP2/NLRC4 oligomer. Because the N-terminus of the NBD faces the core of the ring, this brings the N-terminal CARDs into close proximity (Fig 3E) (Zhang et al., 2015). The NLRC4 CARD fused to GFP forms a filament in vitro (Zhang et al., 2015), although the structure of this filament has not been determined. Based on this and by analogy to other death-fold domain filaments, the NLRC4 CARDs are predicted to form a short filament above the core of the oligomeric ring (Zhang et al., 2015). However, filament assembly will depend on the constraints imposed by the linker between the CARD and NOD. 


\subsection{The inflammasome adaptor ASC amplifies the signal and bridges the interaction of PRRs with effector caspases}

The inflammasome adaptor ASC consists of an N-terminal PYD and a C-terminal CARD, with which it can be recruited to inflammasome initiators with PYDs or CARDs, respectively. The presence of a flexible linker between the two domains allows each domain to interact independently (de Alba, 2009) (Fig. 4A) and each domain has the ability to form filaments in vitro (Lu et al., 2014b; Sborgi et al., 2015; Schmidt et al., 2016) and upon overexpression in vivo (Masumoto et al., 2001).

\subsubsection{Nucleation of ASC PYD filaments by PYD-containing PRRs}

The structure of the ASC PYD filament was solved by cryo-EM (Lu et al., 2014b) and also by solid state NMR (Sborgi et al., 2015), revealing a triple helical filament (Fig. 4B), which exemplifies the use of the conserved death-fold interactions by six faces of each monomer. The type I interaction mediates the dominant interactions forming a single helical strand; a type Ia surface interacts with the type Ib surface of an adjacent domain in an individual helical strand. The type II and III interactions mediate interactions between the three strands of the triple helix. This process of filament formation is a cooperative assembly mechanism, because the molecules recruited downstream have multiple surfaces to bind to (Fig. 4C). Once initiated, the filaments can continue extending in a prion-like manner (Cai et al., 2014) and all the ASC in a cell can become polymerized within minutes (Cheng et al., 2010; Fernandes-Alnemri et al., 2007). ASC CARDs on the side of the ASC PYD filament are predicted to cluster using similar death-fold interactions (Lu et al., 2014b) (Fig. 4C). Because extension of the ASC PYD filament increases the capacity for caspase-1 recruitment and subsequent activation, continued ASC PYD polymerization would amplify the response.

AIM2 PYD can initiate formation of ASC PYD filaments in vitro and consistent with a "seeding" role, AIM2 PYDs are found at one end of the filament (Lu et al., 2014b). Thus in vivo, the AIM2 PYDs that extend from the side of the AIM2 HIN filament are predicted to nucleate radiating ASC PYD filaments (Fig. 5A). Although the mechanism of NLRP3 activation is unknown, a truncated NLRP3 construct with the NOD and PYD can also induce ASC PYD filaments (Lu et al., 2014b). Thus, NLRP-type PRRs are likely to oligomerize similarly to NLRC4 and allow clustering of the associated PYD and subsequently induce ASC PYD filaments. In agreement, AIM2 and NLRP3 activation can initiate ASC PYD filaments in vivo (Dick et al., 2016). Mutations of the type I, II and III surfaces of AIM2 and NLRP3 PYDs diminish their ability to induce ASC PYD filaments (Lu et al., 2014a). Furthermore, mutations of ASC PYD that diminish its self-association also diminish the interaction with AIM2 and NLRP3 PYDs (Vajjhala et al., 2015; Vajjhala et al., 2012). These data are consistent with the selfassociation surfaces being used for the interaction between the PYDs of the PRRs and ASC. Furthermore, the structural similarity between the AIM2 PYD and ASC PYD filaments (Morrone et al., 2015) is consistent with the short helical segment generated by AIM2 PYD forming a template that recruits and nucleates an ASC PYD filament using the same interaction surfaces used by each PYD to self-associate.

\subsubsection{Nucleation of ASC PYD filaments by the NAIP/NLRC4 oligomer}


ASC filaments can be detected upon activation of a NAIP/NLRC4 inflammasome (Schmidt et al., 2016). It is proposed that the clustered CARDs of a NAIP2/NLRC4 oligomer first recruit ASC molecules via CARD interactions and then the ASC PYDs cluster and nucleate an ASC PYD filament in a manner similar to nucleation by PYD-containing PRRs (Fig. 5B).

\subsubsection{Condensation of ASC filaments by ASC CARD interactions to form a compact speck.}

ASC CARDs are exposed on the ASC PYD filament (Fig. 4C) and have been shown to mediate the condensation of ASC filaments into a speck in vivo (Dick et al., 2016; Proell et al., 2013; Schmidt et al., 2016). Although ASC CARDs can form a filament in vitro and upon high-level expression in vivo (Morrone et al., 2015; Schmidt et al., 2016), the CARDs linked to the ASC PYD filament are likely to be restrained to form only a short helical segment in vivo. The ASC speck is visible by fluorescence microscopy (Broz et al., 2010; Sagulenko et al., 2013; Schmidt et al., 2016) and has become synonymous with inflammasome activation.

\subsubsection{Nucleation of procaspase-1 CARD filaments by ASC CARDs.}

ASC CARDs also recruit procaspase-1, which consists of an N-terminal CARD and a catalytic domain. Knowing that GFP-ASC CARDs can nucleate caspase-1 CARD filaments in vitro (Lu et al., 2014b), the clustered ASC CARDs are expected to nucleate procaspase-1 CARD filaments in vivo and allow proximity-induced dimerization and activation of procaspase-1 (Fig. 6). However, the specific orientation of caspase-1 required for its activation, and whether this is achieved within a single filament as depicted in Figure 6, has not been established. Activated caspase-1 can then process the pro-inflammatory cytokines proIL-1 $\beta$ and proIL-18, which initiate inflammation (Rathinam and Fitzgerald, 2016), and gasdermin D, which induces pyroptosis (Kayagaki et al., 2015; Shi et al., 2015).

\subsubsection{Nucleation of procaspase-1 CARD filaments by NLRC4 CARDs of the NAIP/NLRC4 oligomer.}

The NAIP/NLRC4 oligomer as well as GFP-NLRC4 CARDs, which form a filament, can induce procaspase-1 CARD filaments in vitro (Zhang et al., 2015). This suggests direct recruitment and activation of procaspase-1 by the NAIP2/NLRC4 oligomer is possible in vivo. In some agreement, activation of NAIP/NLRC4 in the absence of ASC polymerization induces pyroptosis in vivo (Dick et al., 2016; Schmidt et al., 2016). However, proIL-1 $\beta$ processing was greatly diminished. Furthermore, processing of procaspase-1 was not detected upon activation of NLRC4-dependent inflammasomes in the absence of ASC (Mariathasan et al., 2004). Thus, ASC is required for optimal activation and processing of procaspase- 1 to mediate both proIL-1 $\beta$ cleavage and pyroptosis and in its absence, procaspase-1 is not processed but is activated to a form that is only capable of mediating pyroptosis (Dick et al., 2016; Lage et al., 2014; Mariathasan et al., 2004).

\subsubsection{Nucleation of procaspase-8 DED filaments by ASC PYD.}

Caspase- 8 recruitment and activation by death receptor signaling complexes is well established (Salvesen and Walsh, 2014) and the inflammasome is a newly recognized platform for caspase-8 activation (Man et al., 2013; Pierini et al., 2012; Sagulenko et al., 2013). Procaspase-8 consists of a Cterminal catalytic domain and two N-terminal death effector domains (DEDs), which also belong to the 
death-fold family. Procaspase-8 DEDs form filaments with a similar helical symmetry to that of the ASC PYD filament (Fu et al., 2016). ASC PYD interacts with the procaspase-8 DEDs via an unusual non-homotypic interaction to nucleate procaspase-8 DED filaments that extend from the ASC speck (Sagulenko et al., 2013; Vajjhala et al., 2015) (Fig. 6). In vitro, ASC promotes polymerization of procaspase-8 DED filaments and is detected at one end of the procaspase- 8 filament (Vajjhala et al., 2015). Thus, recruitment of procaspase- 8 DEDs may terminate the ASC PYD filament. However, ASC CARDs can recruit additional ASC molecules to nucleate an ASC PYD filament via a mechanism similar to that proposed for the nucleation of ASC PYD filaments by the NAIP/NLRC4 oligomer (Fig. 5B) (Schmidt et al., 2016). Interestingly, when co-expressed with ASC and AIM2, full-length procaspase-8 does not form radiating filaments in vivo like the DEDs, but instead is condensed to form a speck. This suggests that the catalytic domains from separate procaspase- 8 filaments interact to cross-link the filaments (Vajjhala et al., 2015). Inter-filament interactions may be important for proximity-induced dimerization and activation of procaspase- 8 to induce apoptotic cell death.

\subsection{Co-operative assembly formation in the RLR and TLR signaling pathways}

Oligomerization of members of the death-fold superfamily has also been shown to be central to the signaling pathways downstream of RIG-I-like receptors (RLRs) and Toll-like receptors (TLRs).

\subsection{The RLR family}

The RLR family members recognize viral RNA in the cytosol and activate antiviral signaling pathways, leading to the production of type-I-interferons (IFNs) and other pro-inflammatory cytokines (Andrejeva et al., 2004; Yoneyama et al., 2004). The family consists of three members: retinoic acidinducible gene 1 (RIG-I), melanoma differentiation-associated gene 5 (MDA5) and laboratory of genetics and physiology-2 (LGP2). RIG-I and MDA5 share the same domain architecture, consisting of N-terminal tandem CARDs (2-CARD), a central DExD/H motif helicase domain and a C-terminal domain (CTD). The latter two domains together function as an RNA-recognition unit, forming a ringlike structure around dsRNA (Jiang et al., 2011; Kowalinski et al., 2011; Luo et al., 2011; Wu et al., 2013), while the N-terminal CARDs interact with the mitochondrial anti-viral signaling (MAVS) adaptor (also known as CARD adapter inducing IFN $\beta$ (Cardif), virus-induced signaling adapter (VISA), or IFN $\beta$ promoter stimulator 1 (IPS-1)), leading to activation of antiviral signaling pathways (Kawai et al., 2005; Meylan et al., 2005; Seth et al., 2005; Xu et al., 2005). Although RIG-I and MDA5 share the same domain architecture and the same signaling adaptor, they recognize distinct features of viral RNAs (Baum et al., 2010; Feng et al., 2012; Goubau et al., 2014; Hornung et al., 2006; Kato et al., 2008; Pichlmair et al., 2006; Triantafilou et al., 2012) and detect different groups of viruses (Gitlin et al., 2006; Kato et al., 2006; Loo et al., 2008), and thus play non-redundant roles in the antiviral innate immune response. LGP2 contains a helicase domain and a CTD, but lacks CARDs, which are usually critical for downstream signaling. The specific role of LGP2 in RLR signaling has therefore been more difficult to elucidate, but growing evidence suggest a role for LGP2 as a positive regulator of antiviral responses (Bruns et al., 2014; Satoh et al., 2010; Venkataraman et al., 2007). 


\subsubsection{Receptor oligomerization}

Upon binding to viral dsRNA, both RIG-I and MDA5 can cooperatively assemble into a filament (Berke and Modis, 2012; Berke et al., 2012; Patel et al., 2013; Peisley et al., 2011; Peisley et al., 2013; Wu et al., 2013), resulting in clustering of the N-terminal CARDs, which forms a scaffold for binding and oligomerization of the MAVS CARDs. In the inactive state, the tandem RIG-I CARDs have been shown to be protected from self-association by interaction with the helicase domain. Upon viral RNA binding, conformational changes release the CARDs from the helicase domain, enabling them to selfassociate and interact with MAVS (Jiang et al., 2011; Kowalinski et al., 2011; Luo et al., 2011). RIG-I and MDA5 tandem CARD oligomerization is further promoted by both non-covalent and covalent K63-linked polyubiquitination (Gack et al., 2007; Jiang et al., 2012; Peisley et al., 2014; Zeng et al., 2010).

\subsubsection{MAVS filament formation}

MAVS activates RIG-I and MDA5-dependent antiviral signaling by recruiting the E3 ubiquitin ligases TRAF2, 5 and 6, which in turn activate cytosolic kinases, TBK1 and IKK, and subsequently the transcription factors IRF3/7 and NF-אB (Vazquez and Horner, 2015). MAVS contains an N-terminal CARD involved in oligomerization and RIG-I/MDA5 interaction, a central non-structured region of approximately 400 amino acids with TRAF2- and TRAF5-binding sites, and a C-terminal transmembrane (TM) domain required for anchoring to the mitochondrial membrane. Recent studies have shown that, similar to the inflammasomes, MAVS-dependent RIG-I/MDA-5 signaling involves a SCAF mechanism resulting in filament formation of MAVS on the mitochondria (Hou et al., 2011) (Fig. 7). The filament is formed by the MAVS CARDs, and is necessary for recruitment of TRAF2 and TRAF5 and activation of the downstream signaling pathway.

The structure of the MAVS ${ }^{\text {CARD }}$ filament was solved by cryo-EM at $3.6 \AA$ resolution and revealed a left-handed single-stranded helix of MAVS ${ }^{\text {CARD }}$ subunits (Wu et al., 2014). Similar to inflammasome PYD/CARD filaments, each MAVS ${ }^{\mathrm{CARD}}$ subunit interacts with six nearest neighbours, using six distinct surface areas forming three types of intermolecular interactions. Crystal structures of the RIGI tandem CARDs alone (Peisley et al., 2014) and in complex with MAVS ${ }^{\text {CARD }}$ (Wu et al., 2014) revealed that tandem RIG-I CARDs act as a template for assembly formation of MAVS ${ }^{\text {CARD }}$, by forming a helical tetrameric structure and recruiting MAVS ${ }^{\mathrm{CARD}}$ along its helical trajectory, in what has been termed the lock-washer mechanism. Although crystal structures are not available for MDA5 oligomers alone or in complex with MAVS ${ }^{\mathrm{CARD}}$, it is likely that MDA5 induces formation of MAVS filaments via a similar mechanism.

\subsection{The TLR family and TIR domain-containing adaptor proteins}

TLRs are single-pass transmembrane receptors that contain an extracellular LRR domain involved in PAMP/DAMP recognition, and a cytosolic Toll/interleukin-1 receptor (TIR) domain required for signal transduction (Akira et al., 2006). TLRs localize to the cell surface or to the intracellular membrane-bound compartments such as the endosomes. The TLR family members recognize a wide variety of PAMPs, including lipopolysaccharides, lipopeptides and flagellin (surface TLRs) and viral and bacterial nucleic acids (endosomal TLRs). PAMP recognition by TLRs leads to activation of 
transcription factors NF- $\mathrm{B}, \mathrm{AP}-1$ and IRFs to induce anti-pathogen responses and inflammation (Gay et al., 2014).

PAMP recognition by TLRs leads to recruitment of a single, or specific combination of, intracellular TIR domain-containing adaptor proteins via homotypic TIR-domain interactions (Ve et al., 2012). The adaptors involved in TLR signaling comprise MyD88 (myeloid differentiation primary response gene 88), MAL (MyD88 adaptor-like protein), TRIF (TIR domain-containing adaptor protein inducing IFN), TRAM (TRIF-related adaptor molecule) and SARM (sterile- $\alpha$ and armadillo motif).

MyD88 is required for signaling by all TLRs except for TLR3, which uses TRIF alone. The C-terminal TIR domain of MyD88 interacts directly with the TIR domains of activated receptors, or indirectly via the adaptor protein MAL (Medzhitov et al., 1998; Yamamoto et al., 2002). MyD88 also has a Nterminal death domain (DD), which recruits IRAK4 (interleukin-1 receptor- associated kinase 4) through DD interactions (Wesche et al., 1997). This results in activation of the MAP kinase and NF$\kappa \mathrm{B}$ pathways, leading to production of inflammatory cytokines. MAL, also called TIRAP (Toll/interleukin-1 domain- containing adaptor protein) is a bridging adaptor between TLRs and MyD88 (Fitzgerald et al., 2001). PIP2 (phosphatidylinositol-4,5-bisphosphate) binding localizes MAL to the plasma membrane, where it recruits MyD88 to TLR2 and TLR4 via homotypic TIR-domain interactions (Kagan and Medzhitov, 2006). MAL has recently also been shown to be required for endosomal MyD88-dependent TLR9 signaling in response to viral infection (Bonham et al., 2014).

TRIF, also called TICAM-1 (TIR-containing apdaptor molecule-1) is the sole signaling adaptor for TLR3, and also associates with TLR4 via TRAM (Hoebe et al., 2003; Oshiumi et al., 2003a; Yamamoto et al., 2003). TRIF activates both NF-KB and IRF3, resulting in production of both proinflammatory cytokines and type-1-IFN. TRAM, also called TICAM-2, is responsible for recruitment of TRIF to the activated and endocytosed TLR4 via homotypic TIR-domain interactions and operates both at the plasma membrane and the endosomes (Kagan et al., 2008; Oshiumi et al., 2003b; Rowe et al., 2006). The fifth adaptor, SARM, is the most conserved TLR adaptor protein with homologs identified in Drosophila and Caenorhabditis elegans. Human SARM can act as a specific inhibitor of TLR3 and TLR4 signaling mediated by TRIF (Carty et al., 2006), but recently SARM has also been shown to have functional roles in apoptosis and antiviral innate immune responses (reviewed by (Panneerselvam and Ding, 2015)), and to be an executioner of axon degeneration, a self-destruction program that promotes the localized clearance of damaged axon segments (Gerdts et al., 2013; Osterloh et al., 2012).

\subsubsection{Receptor dimerization triggers MyD88 and TRIF oligomerization}

Ligand binding to a TLR causes dimerization of the receptors or conformational changes of existing dimers. To date, the structures of TLR3-5 and TLR7-8 extracellular domain homodimers and the TLR1/2 and TLR1/6 extracellular domain heterodimers in complex with their physiological or synthetic ligands have been reported (Liu et al., 2008; Song and Lee, 2012; Tanji et al., 2013; Yoon et al., 2012; Zhang et al., 2016). The dimeric arrangements of the LRR domains are similar in all of the TLR-ligand complex structures, with the two $\mathrm{C}$ termini converging in the middle, which presumably drives the intracellular TIR domains to self-associate and subsequently recruit TIR domain-containing 
adaptor proteins via homotypic TIR-domain interactions to initiate signaling (Gay et al., 2014) (Fig. 8). Recruitment of MyD88 to the activated membrane-bound TLR induces formation of an oligomeric MyD88-IRAK complex called the myddosome. Biophysical studies have shown that the DD domain of MyD88 exists in a rapid monomer-oligomer equilibrium in solution, but in the presence of the IRAK-4 DD, stable assemblies with stoichiometries of 7:4 and 8:4 are formed (Lin et al., 2010; Motshwene et al., 2009). The crystal structure of a MyD88, IRAK4 and IRAK2 DD complex revealed a helical assembly consisting of six MyD88, four IRAK4, and four IRAK2 DDs (Lin et al., 2010) (Fig. 8). As observed in the inflammasome and MAVS filaments, the DDs in the myddosome interact with each other through three types of asymmetric interaction modes. The structure suggests a sequential assembly process in which a receptor-induced homo-oligomer of MyD88 forms first and provides a platform for recruitment of four IRAK4 and then four IRAK2 molecules. Similar to the lock-washer mechanism described for the RIG-I/MDA5-MAVS interaction, the DDs of MyD88 form a helical template that is extended first by IRAK4 and then IRAK2. myddosome formation brings the kinase domains of IRAKs into proximity for phosphorylation and activation.

In comparison to MyD88 signaling, much less is known about TRIF signaling (Ullah et al., 2016), but live-cell imaging and confocal immunofluorescence analyses have shown that TRIF alters its distribution profile from a diffuse cytoplasmic form to a speckle-like structure in response to TLR3 interaction with dsRNA, which suggests that oligomeric TRIF complexes are also formed in response to ligand activation (Funami et al., 2007). Yeast two-hybrid and co-immunoprecipitation studies using TRIF deletion mutants revealed that both the TIR domain and the C-terminal region, but not the Nterminal domain are required for TRIF oligomerization (Funami et al., 2008). TRIF does not contain a DD, but the C-terminal region harbors a RIP homotypic interaction motif (RHIM), which in RIP1 and RIP3 kinases have been shown to facilitate the assembly of the functional filamentous signaling complex that mediates necroptosis (Li et al., 2012).

\subsubsection{The TIR domain signalosome}

The adaptor MAL has been shown to be required for TLR4-induced myddosome assembly and is present within it (Bonham et al., 2014). Forced dimerization of the MyD88 TIR domain constitutively activates signaling (Fekonja et al., 2012), suggesting that MAL and MyD88 form an oligomeric platform through TIR-domain interactions upon TLR activation, which in turn promotes the assembly of the myddosome via DD interactions. The molecular mechanisms underpinning adaptor recruitment to TLRs via homotypic TIR-domain interactions are currently not well understood due to the difficulty of reconstituting stable TIR domain oligomers. This suggests that weak interactions are general feature of the TIR-domain function, and that a high local concentration is required for stabilizing the interaction, which in normal signaling can be achieved either by membrane attachment or in the context of a larger assembly.

Crystal structures are available for the TIR domains of human TLR1-2, TLR6, TLR10, IL-1RAPL, MyD88 and MAL (Jang and Park, 2014; Khan et al., 2004; Nyman et al., 2008; Snyder et al., 2013; Valkov et al., 2011; Xu et al., 2000), and the Toll-related receptor TRR-2 from the lower metazoan 
Hydra magnipapillata (PDB ID 4W8G, 4W8H). In addition, NMR structures have been determined for the TIR domains of MyD88, TRAM and TRIF (Enokizono et al., 2013; Ohnishi et al., 2009). Crystal contact analysis, and site directed mutagenesis-restrained docking of crystal and NMR structures or homology models have been used extensively to gain insight into the TIR domain assembly process (Bovijn et al., 2013; Bovijn et al., 2012; Enokizono et al., 2013; Guven-Maiorov et al., 2015; Khan et al., 2004; Nunez Miguel et al., 2007; Ohnishi et al., 2009; Tao et al., 2002; Toshchakov et al., 2011; Vyncke et al., 2016). Although some common broad trends in homotypic TIR-domain association modes have been identified, there is overall little consensus among the different assembly models (Nimma et al., 2017; Ve et al., 2015). Many of the earlier models assume a 1:1 or 2:1 receptor:adaptor stoichiometry, which fails to explain how receptor dimerization can induce myddosome formation (Bovijn et al., 2013; Bovijn et al., 2012; Nunez Miguel et al., 2007). However, two more recent distinct models try to rationalize how receptor dimerization can lead to myddosome formation (GuvenMaiorov et al., 2015; Vyncke et al., 2016). In one of these models, which is based on docking restrained by extensive mutagenesis data, MyD88 TIR domains assemble into a left-handed helix by combining a symmetric and an asymmetric mode of homotypic TIR-domain interactions (Vyncke et al., 2016). Extension of the helix would allow assembly of multiple myddosomes, which is consistent with the ability of TLRs to activate a large transcriptional response in response to extremely low concentrations of PAMPs (Cheng et al., 2015; Gioannini and Weiss, 2007; Stylianou et al., 1992), and is similar to the SCAF models for inflammasome activation and MAVS-dependent RIG-I/MDA5 signaling (Lu et al., 2014b; Wu et al., 2014). Although this model is consistent with observed homotypic TIR-domain interaction modes, the significant variations observed in TIR:TIR interactions in different mammalian proteins could give rise to TIR-domain oligomers with different architectures. To fully elucidate the molecular mechanisms of TIR-domain assembly formation in TLR signaling and the exact nature of the interfaces, structural information on stable oligomeric assemblies will be required.

\section{Conservation of SCAF in plants and fungi}

\subsection{NLRs in other kingdoms of life}

NOD-like receptors can be found in kingdoms of life outside of animals; both fungi and plants have NLR proteins analogous to those found in animals. No NLRs or PRR-like proteins have been identified to date in bacteria; however, proteins containing singular domains associated with PRRs, such as TIR domains, have been identified in some bacterial species.

\subsection{Plant NLRs}

NLR proteins have important roles in the immune systems of plants. These proteins are intracellular receptors employed to detect virulence proteins, such as those secreted into the host by fungal, bacterial and oomycete pathogens, and consequently signal to activate cell death. Unlike animal NLRs, plant NLRs are highly ligand-specific, recognizing only strain-specific virulence proteins (Dangl and Jones, 2001). Regardless of this, plant NLRs have a highly similar domain arrangement to animal NLRs, consisting of an N-terminal signaling domain, central NOD domain, and a C-terminal LRR domain. The major difference from animal NLRs is in the type of domains used to make up the 
receptor. Plant NLRs can be seen as constructed from a medley of components from animal PRRs and apoptotic proteins (Bentham et al., 2016). They often contain an N-terminal TIR domain, also present in animal TLRs, but many instead have a CC domain with a four-helix bundle fold that bears some similarities to a death-fold domain structure (Jones and Dangl, 2006). The central NOD is most similar to that of APAF-1 or CED4, which is referred to as NB-ARC (nucleotide-binding adaptor shared by APAF-1 [apoptotic protease-activating factor 1], R proteins and CED-4) domain (van der Biezen and Jones, 1998). The NB-ARC domain is closely related to but distinct from the NACHT domain of animal NLRs. Proteins with the NACHT or NB-ARC domains make up the two major subfamilies of the STAND family of ATPases (Leipe et al., 2004). Homotypic interactions between N-terminal TIR and CC effector domains have been established as an essential event for the NLR to effectively activate cell death (Bernoux et al., 2011; Schreiber et al., 2016; Williams et al., 2014). Interestingly, these N-terminal interactions have been demonstrated to be weak and transient, and therefore it has been proposed that the signaling domain self-association is mediated by NOD oligomerization (Bernoux et al., 2011; Schreiber et al., 2016; Williams et al., 2014). Currently, there is no structural evidence for NOD oligomerization in plant NLRs; however, recent biochemical analysis of the Arabidopsis NLR "Resistance to Personospora Parasitica 1" (RPP1) demonstrated that it is capable of ligand-induced, NB-ARC domain-dependent self-association, and this process is vital for RPP1mediated cell death (Schreiber et al., 2016). Similarities between plant and animal NLR structure and function have led to the hypothesis that plant NLRs signal via cooperative assembly to produce a "resistosome" signaling complex, similar to that of the inflammasome (Bentham et al., 2016).

\subsection{Fungal NLRs}

Analyses of fungal genomes have identified extensive repertoires of NLR and STAND-like proteins. Fungal NLRs have been implicated in a process called heterokaryon incompatibility that involves nonself recognition and activation of cell death. These proteins share a similar tripartite domain architecture as their plant and animal counterparts, with an N-terminal signaling domain, central NODlike domain, and C-terminal repeat super-structure (Koonin and Aravind, 2000; Saupe et al., 1995). Unlike animals and plants however, there is high variability in the potential domain arrangement of fungal NLRs, with the exception of the NOD domain, which is primarily dominated by the NACHT domain, although NB-ARC-containing fungal NLRs have also been identified (Dyrka et al., 2014). There are $>12$ different N-terminal domains associated with fungal NLRs, and three major types of Cterminal repeat domains (WD, ANK and TPR) (Dyrka et al., 2014). The N-terminal domains of fungal NLRs can be separated into two classes based on proposed functions. Class $1 \mathrm{~N}$-terminal domains have proposed enzymatic functions and have potential involvement in cell-death activation. Class $2 \mathrm{~N}$ terminal domains are more analogous to plant and animal N-terminal domains, acting as adaptors that may signal through homotypic interactions to recruit downstream signaling partners (Dyrka et al., 2014). Two domains in class 2 NLRs are noteworthy: the prion HeLo domain of Het-s, which can substitute the PYD of NLRP3 to create a chimeric protein capable of activating pro-caspase-1 (Cai et al., 2014); and the HET domain of HET-E, which shares remote structural similarities to the TIR domains of plant and animal PRRs (Dyrka et al., 2014). Biochemical and structural information of fungal NLRs is scarce and so it is unclear if these proteins assemble into higher-order oligomers; 
however, considering the available data and their shared similarities to animal NLRs, this is a likely possibility.

\section{Conclusions}

The architecture of the signaling complexes induced by PRRs allows rapid co-operative assembly, signal amplification and provides a scaffold for proximity-induced activation. There are two types of co-operative assembly mechanisms observed in the different complexes. In the case of the death-fold filaments, including the PYD, CARD and DD filaments and the AIM2 HIN domain/dsDNA oligomer, co-operative assembly occurs via the presentation of multiple interaction sites by the preceding components that facilitate downstream recruitment. However, a second type of mechanism observed in the NAIP2/NLRC4 complex is induction of conformational changes in NLRC4 upon recruitment to the complex, which enables recruitment of a subsequent NLRC4 monomer.

There are many advantages of SCAF. First, the low affinity of the receptors and downstream components prevents interaction of the receptors in the absence of activation-induced clustering and ensures a PAMP-triggered signaling event. Second, it allows a rapid amplification process, whereby low-level PAMP concentration and activation of just a few receptors can recruit multiple downstream adaptors and effectors and amplify the signal immensely (Hauenstein et al., 2015). Third, in the case of the inflammasome for example, it initiates a self-perpetuating system that continues to recruit downstream proteins. Furthermore, because the complex is self-perpetuating, it can continue signaling upon transfer from one cell to another (Franklin et al., 2014). Thus, the SCAF mechanism is perfectly suited to enhance the effect of PRRs as a first line of defense in innate immunity.

\section{Conflict of interest}

The authors have no financial or personal interests to disclose.

\section{Submission declaration}

This article has not been published previously elsewhere although some background information included in the paper is widely available elsewhere. The authors included in this paper have contributed significantly to the overall knowledge and information included in this article.

\section{Acknowledgements}

The work in the authors' laboratories was supported by the National Health and Medical Research Council (NHMRC grants 1003326, 1107804, 1071659, 1050651, and 1109738) and the Australian Research Council (ARC Discovery Projects DP120100685, DP160102244). BK is NHMRC Principal Research Fellow (1003325, 1110971), KJS is NHMRC Senior Research Fellow (1059729), TV is funded by ARC DECRA (DE170100783). 


\section{Figure legends}

Fig. 1. Overview of inflammasome assembly. Activation and oligomerization of pattern recognition receptors (PRRs) enables them to recruit and nucleate filaments of the adaptor protein ASC. The ASC filament in turn nucleates filaments of procaspases -1 and -8 .

Fig. 2. The AIM2/dsDNA inflammasome initiation complex. $A$, Structure of the AIM2 HIN domain bound to dsDNA (PDB ID 3RN2) (Jin et al., 2012). Two HIN domains (colored pink and brown) are shown and the individual oligosaccharide binding domains (OB1 and OB2) are indicated on each HIN domain. B, Structure of the AIM2 PYD (PDB ID 3VD8) (Jin et al., 2013), which is a typical death-fold domain containing six $\alpha$-helices in an anti-parallel arrangement. $C$, Model to illustrate the polymerization of the AIM2 HIN domains (OB1 and OB2 shown as pink, brown rectangles) along dsDNA and the clustering of the AIM2 PYDs (yellow hexagons).

Fig. 3. The NAIP2/NLRC4 inflammasome initiation complex. $A$, Schematic representation of NLRC4 and NAIP2, indicating the position of the nucleotide binding and oligomerization domains (NODs), which comprise the nucleotide binding domain (NBD), helical domain 1 (HD1), and the winged helical domain (WHD); helical domain 2 (HD2); the leucine-rich repeat (LRR) domain; and the N-terminal CARD or BIR domain. $B$, Structure of the NLRC4 monomer in the inactive conformation (PDB ID 4KXF) (Hu et al., 2013) and a subunit of the NAIP2/NLRC4 oligomer (subunit from PDB ID 3JBL) (Zhang et al., 2015) in the active conformation. $C$, structure of the NAIP2/NLRC4 oligomer (PDB ID 3JBL). Domains are colored as in $A$ and $B$. $D$, Model for co-operative assembly of the NAIP2/NLRC4 oligomer via an induced conformational change. An activated monomer of NLRC4 (subunit from PDB ID 3JBL) is proposed to use a basic surface of the NOD to interact with an acidic surface of the NOD from an inactive monomer of NLRC4 (PDB ID 4KXF). The interaction induces conformational changes in the inactive monomer to the active conformation that exposes the basic surface, which can then interact with another monomer. Some of the charged residues in the basic and acidic surfaces are indicated in blue and red, respectively. $E$, the NAIP2/NLRC4 oligomer (PDB ID 3JBL), with one subunit colored red to indicate a NAIP2 monomer, showing the predicted position of the NLRC4 CARDs.

Fig. 4. The ASC filament. $A$, Structure of ASC (PDB ID 2KN6) showing ASC PYD and ASC CARD separated by a flexible linker. $B$, Structure of the ASC PYD triple helical filament (PDB ID 3J63) (Lu et al., 2014b). One monomer is boxed to show the six interaction surfaces (type Ia, Ib, IIa, IIb, IIIa, IIIb), which are typical of death-fold domains. $C$, Schematic diagram of the ASC PYD filament showing how a downstream recruited ASC PYD is presented with multiple interaction sites to assemble co-operatively. The CARDs on the side of the ASC PYD filament that cluster to form a short filament are also shown.

Fig. 5. Model for initiation of ASC filaments by inflammasome initiation complexes. $A$, AIM2 HIN domain polymerizes on dsDNA and the AIM2 PYDs cluster and recruit ASC via its PYD to nucleate 
an ASC PYD filament. $B$, The clustered CARDs of the NAIP2/NLRC4 oligomer recruit ASC via its CARD. Clustering of ASC CARDs drives clustering of ASC PYDs, which can then recruit further ASC PYDs to initiate an ASC PYD filament.

Fig. 6. Model for recruitment and activation of procaspases- 1 and -8 . The AIM $2 /$ dsDNA inflammasome initiation complex nucleates an ASC PYD filament. Clustered ASC CARDs on the side of the ASC filament recruit procaspase-1 and nucleate procaspase-1 CARD filaments. Catalytic domains on the sides of the procaspase-1 CARD filament can dimerize and become activated. Procaspase-8 DEDs are recruited to the ASC PYD filament and a DED filament is nucleated. The procaspase- 8 catalytic domains on the side of the filament can also dimerize and become activated.

Fig. 7. Model of activated RIG-I/MDA-5:MAVS complexes. Viral RNA binding induces conformational changes in the RIG-I/MDA-5 receptors resulting in release of the tandem CARDs from the helicase domain. The receptor CARDs can then self-associate and form a template for MAVS recruitment and filament formation on the mitochondria.

Fig. 8. Working model for activation of MyD88 dependent TLR signaling. PAMP binding to TLRs results in self-association of the cytosolic TIR domains and recruitment of adaptor proteins such as MAL and MyD88 via TIR:TIR domain interactions. MAL is membrane associated through interaction with PIP2?? Need some comment on that feature of the diagram. Recruitment of multiple MyD88 molecules subsequently leads to recruitment of IRAKs via DD:DD interactions and formation of the myddosome. The structural basis for myddosome formation and PAMP recognition by many TLRs has been established, but how receptor and adaptor TIR domains assemble to promote formation of the myddosome is poorly understood. 


\section{References}

Akira, S., Uematsu, S., and Takeuchi, O. (2006). Pathogen recognition and innate immunity. Cell $124,783-801$.

Andrejeva, J., Childs, K.S., Young, D.F., Carlos, T.S., Stock, N., Goodbourn, S., and Randall, R.E. (2004). The V proteins of paramyxoviruses bind the IFN-inducible RNA helicase, mda-5, and inhibit its activation of the IFN-beta promoter. Proceedings of the National Academy of Sciences of the United States of America 101, 17264-17269.

Antonopoulos, C., Russo, H.M., El Sanadi, C., Martin, B.N., Li, X., Kaiser, W.J., Mocarski, E.S., and Dubyak, G.R. (2015). Caspase-8 as an effector and regulator of NLRP3 inflammasome signaling. The Journal of biological chemistry.

Arcus, V. (2002). OB-fold domains: a snapshot of the evolution of sequence, structure and function. Current opinion in structural biology 12, 794-801.

Baum, A., Sachidanandam, R., and Garcia-Sastre, A. (2010). Preference of RIG-I for short viral RNA molecules in infected cells revealed by next-generation sequencing. Proceedings of the National Academy of Sciences of the United States of America 107, 16303-16308.

Bentham, A., Burdett, H., Anderson, P.A., Williams, S.J., and Kobe, B. (2016). Animal NLRs provide structural insights into plant NLR function. Annals of botany.

Berke, I.C., and Modis, Y. (2012). MDA5 cooperatively forms dimers and ATP-sensitive filaments upon binding double-stranded RNA. The EMBO journal 31, 1714-1726.

Berke, I.C., Yu, X., Modis, Y., and Egelman, E.H. (2012). MDA5 assembles into a polar helical filament on dsRNA. Proceedings of the National Academy of Sciences of the United States of America 109, 18437-18441.

Bernoux, M., Ve, T., Williams, S., Warren, C., Hatters, D., Valkov, E., Zhang, X., Ellis, J.G., Kobe, B., and Dodds, P.N. (2011). Structural and functional analysis of a plant resistance protein TIR domain reveals interfaces for self-association, signaling, and autoregulation. Cell host \& microbe 9, 200-211.

Bonham, K.S., Orzalli, M.H., Hayashi, K., Wolf, A.I., Glanemann, C., Weninger, W., Iwasaki, A., Knipe, D.M., and Kagan, J.C. (2014). A promiscuous lipid-binding protein diversifies the subcellular sites of toll-like receptor signal transduction. Cell 156, 705-716.

Bovijn, C., Desmet, A.S., Uyttendaele, I., Van Acker, T., Tavernier, J., and Peelman, F. (2013). Identification of binding sites for myeloid differentiation primary response gene 88 (MyD88) and Toll-like receptor 4 in MyD88 adapter-like (Mal). The Journal of biological chemistry 288, 1205412066.

Bovijn, C., Ulrichts, P., De Smet, A.S., Catteeuw, D., Beyaert, R., Tavernier, J., and Peelman, F. (2012). Identification of interaction sites for dimerization and adapter recruitment in Toll/interleukin-1 receptor (TIR) domain of Toll-like receptor 4. The Journal of biological chemistry 287, 4088-4098.

Broz, P., Newton, K., Lamkanfi, M., Mariathasan, S., Dixit, V.M., and Monack, D.M. (2010). Redundant roles for inflammasome receptors NLRP3 and NLRC4 in host defense against Salmonella. The Journal of experimental medicine 207, 1745-1755.

Bruns, A.M., Leser, G.P., Lamb, R.A., and Horvath, C.M. (2014). The innate immune sensor LGP2 activates antiviral signaling by regulating MDA5-RNA interaction and filament assembly. Molecular cell 55, 771-781. 
Cai, X., Chen, J., Xu, H., Liu, S., Jiang, Q.X., Halfmann, R., and Chen, Z.J. (2014). Prion-like polymerization underlies signal transduction in antiviral immune defense and inflammasome activation. Cell 156, 1207-1222.

Carty, M., Goodbody, R., Schroder, M., Stack, J., Moynagh, P.N., and Bowie, A.G. (2006). The human adaptor SARM negatively regulates adaptor protein TRIF-dependent Toll-like receptor signaling. Nature immunology 7, 1074-1081.

Cheng, J., Waite, A.L., Tkaczyk, E.R., Ke, K., Richards, N., Hunt, A.J., and Gumucio, D.L. (2010). Kinetic properties of ASC protein aggregation in epithelial cells. Journal of cellular physiology 222, 738-747.

Cheng, Z., Taylor, B., Ourthiague, D.R., and Hoffmann, A. (2015). Distinct single-cell signaling characteristics are conferred by the MyD88 and TRIF pathways during TLR4 activation. Science signaling 8 , ra69.

Chung, H., Vilaysane, A., Lau, A., Stahl, M., Morampudi, V., Bondzi-Simpson, A., Platnich, J.M., Bracey, N.A., French, M.C., Beck, P.L., Chun, J., Vallance, B.A., and Muruve, D.A. (2016). NLRP3 regulates a non-canonical platform for caspase-8 activation during epithelial cell apoptosis. Cell death and differentiation 23,1331-1346.

Cridland, J.A., Curley, E.Z., Wykes, M.N., Schroder, K., Sweet, M.J., Roberts, T.L., Ragan, M.A., Kassahn, K.S., and Stacey, K.J. (2012). The mammalian PYHIN gene family: phylogeny, evolution and expression. BMC evolutionary biology 12, 140.

Dangl, J.L., and Jones, J.D. (2001). Plant pathogens and integrated defence responses to infection. Nature 411, 826-833.

Danot, O., Marquenet, E., Vidal-Ingigliardi, D., and Richet, E. (2009). Wheel of life, wheel of death: a mechanistic insight into signaling by STAND proteins. Structure 17, 172-182.

de Alba, E. (2009). Structure and interdomain dynamics of apoptosis-associated speck-like protein containing a CARD (ASC). The Journal of biological chemistry 284, 32932-32941. Dick, M.S., Sborgi, L., Ruhl, S., Hiller, S., and Broz, P. (2016). ASC filament formation serves as a signal amplification mechanism for inflammasomes. Nature communications 7, 11929. Diebolder, C.A., Halff, E.F., Koster, A.J., Huizinga, E.G., and Koning, R.I. (2015). Cryoelectron tomography of the NAIP5/NLRC4 inflammasome: implications for NLR activation. Structure 23, 2349-2357.

Dyrka, W., Lamacchia, M., Durrens, P., Kobe, B., Daskalov, A., Paoletti, M., Sherman, D.J., and Saupe, S.J. (2014). Diversity and variability of NOD-like receptors in fungi. Genome biology and evolution 6, 3137-3158.

Enokizono, Y., Kumeta, H., Funami, K., Horiuchi, M., Sarmiento, J., Yamashita, K., Standley, D.M., Matsumoto, M., Seya, T., and Inagaki, F. (2013). Structures and interface mapping of the TIR domain-containing adaptor molecules involved in interferon signaling. Proceedings of the National Academy of Sciences of the United States of America 110, 19908-19913.

Faustin, B., Lartigue, L., Bruey, J.M., Luciano, F., Sergienko, E., Bailly-Maitre, B., Volkmann, N., Hanein, D., Rouiller, I., and Reed, J.C. (2007). Reconstituted NALP1 inflammasome reveals twostep mechanism of caspase-1 activation. Molecular cell 25, 713-724.

Fekonja, O., Bencina, M., and Jerala, R. (2012). Toll/interleukin-1 receptor domain dimers as the platform for activation and enhanced inhibition of Toll-like receptor signaling. The Journal of biological chemistry 287, 30993-31002.

Feng, Q., Hato, S.V., Langereis, M.A., Zoll, J., Virgen-Slane, R., Peisley, A., Hur, S., Semler, B.L., van Rij, R.P., and van Kuppeveld, F.J. (2012). MDA5 detects the double-stranded RNA replicative form in picornavirus-infected cells. Cell reports 2, 1187-1196. 
Fernandes-Alnemri, T., Wu, J., Yu, J.W., Datta, P., Miller, B., Jankowski, W., Rosenberg, S., Zhang, J., and Alnemri, E.S. (2007). The pyroptosome: a supramolecular assembly of ASC dimers mediating inflammatory cell death via caspase-1 activation. Cell death and differentiation 14, 1590-1604. Fitzgerald, K.A., Palsson-McDermott, E.M., Bowie, A.G., Jefferies, C.A., Mansell, A.S., Brady, G., Brint, E., Dunne, A., Gray, P., Harte, M.T., McMurray, D., Smith, D.E., Sims, J.E., Bird, T.A., and O'Neill, L.A. (2001). Mal (MyD88-adapter-like) is required for Toll-like receptor-4 signal transduction. Nature 413, 78-83.

Franklin, B.S., Bossaller, L., De Nardo, D., Ratter, J.M., Stutz, A., Engels, G., Brenker, C., Nordhoff, M., Mirandola, S.R., Al-Amoudi, A., Mangan, M.S., Zimmer, S., Monks, B.G., Fricke, M., Schmidt, R.E., Espevik, T., Jones, B., Jarnicki, A.G., Hansbro, P.M., Busto, P., Marshak-Rothstein, A., Hornemann, S., Aguzzi, A., Kastenmuller, W., and Latz, E. (2014). The adaptor ASC has extracellular and 'prionoid' activities that propagate inflammation. Nature immunology 15, 727-737.

Fu, T.M., Li, Y., Lu, A., Li, Z., Vajjhala, P.R., Cruz, A.C., Srivastava, D.B., DiMaio, F., Penczek, P.A., Siegel, R.M., Stacey, K.J., Egelman, E.H., and Wu, H. (2016). Cryo-EM structure of caspase-8 tandem DED filament reveals assembly and regulation mechanisms of the death-inducing signaling complex. Molecular cell 64, 236-250.

Funami, K., Sasai, M., Ohba, Y., Oshiumi, H., Seya, T., and Matsumoto, M. (2007). Spatiotemporal mobilization of Toll/IL-1 receptor domain-containing adaptor molecule-1 in response to dsRNA. Journal of immunology 179, 6867-6872.

Funami, K., Sasai, M., Oshiumi, H., Seya, T., and Matsumoto, M. (2008). Homo-oligomerization is essential for Toll/interleukin-1 receptor domain-containing adaptor molecule-1-mediated NFkappaB and interferon regulatory factor-3 activation. The Journal of biological chemistry 283 , 18283-18291.

Gack, M.U., Shin, Y.C., Joo, C.H., Urano, T., Liang, C., Sun, L., Takeuchi, O., Akira, S., Chen, Z., Inoue, S., and Jung, J.U. (2007). TRIM25 RING-finger E3 ubiquitin ligase is essential for RIG-I-mediated antiviral activity. Nature 446, 916-920.

Gay, N.J., Symmons, M.F., Gangloff, M., and Bryant, C.E. (2014). Assembly and localization of Tolllike receptor signalling complexes. Nat Rev Immunol 14, 546-558.

Gerdts, J., Summers, D.W., Sasaki, Y., DiAntonio, A., and Milbrandt, J. (2013). Sarm1-mediated axon degeneration requires both SAM and TIR interactions. J Neurosci 33, 13569-13580.

Gioannini, T.L., and Weiss, J.P. (2007). Regulation of interactions of Gram-negative bacterial endotoxins with mammalian cells. Immunologic research 39, 249-260.

Gitlin, L., Barchet, W., Gilfillan, S., Cella, M., Beutler, B., Flavell, R.A., Diamond, M.S., and Colonna, M. (2006). Essential role of mda-5 in type I IFN responses to polyriboinosinic:polyribocytidylic acid and encephalomyocarditis picornavirus. Proceedings of the National Academy of Sciences of the United States of America 103, 8459-8464.

Goubau, D., Schlee, M., Deddouche, S., Pruijssers, A.J., Zillinger, T., Goldeck, M., Schuberth, C., Van der Veen, A.G., Fujimura, T., Rehwinkel, J., Iskarpatyoti, J.A., Barchet, W., Ludwig, J., Dermody, T.S., Hartmann, G., and Reis e Sousa, C. (2014). Antiviral immunity via RIG-I-mediated recognition of RNA bearing 5'-diphosphates. Nature 514, 372-375.

Guo, H., Callaway, J.B., and Ting, J.P. (2015). Inflammasomes: mechanism of action, role in disease, and therapeutics. Nature medicine 21, 677-687.

Guven-Maiorov, E., Keskin, O., Gursoy, A., VanWaes, C., Chen, Z., Tsai, C.J., and Nussinov, R. (2015). The architecture of the TIR domain signalosome in the Toll-like receptor-4 signaling pathway. Sci Rep 5, 13128.

Hauenstein, A.V., Zhang, L., and Wu, H. (2015). The hierarchical structural architecture of inflammasomes, supramolecular inflammatory machines. Current opinion in structural biology $31,75-83$. 
Hoebe, K., Du, X., Georgel, P., Janssen, E., Tabeta, K., Kim, S.O., Goode, J., Lin, P., Mann, N., Mudd, S., Crozat, K., Sovath, S., Han, J., and Beutler, B. (2003). Identification of Lps2 as a key transducer of MyD88-independent TIR signalling. Nature 424, 743-748.

Hornung, V., Ellegast, J., Kim, S., Brzozka, K., Jung, A., Kato, H., Poeck, H., Akira, S., Conzelmann, K.K., Schlee, M., Endres, S., and Hartmann, G. (2006). 5'-Triphosphate RNA is the ligand for RIG-I. Science 314, 994-997.

Hou, F., Sun, L., Zheng, H., Skaug, B., Jiang, Q.X., and Chen, Z.J. (2011). MAVS forms functional prion-like aggregates to activate and propagate antiviral innate immune response. Cell 146, 448461.

Hu, Z., Yan, C., Liu, P., Huang, Z., Ma, R., Zhang, C., Wang, R., Zhang, Y., Martinon, F., Miao, D., Deng, H., Wang, J., Chang, J., and Chai, J. (2013). Crystal structure of NLRC4 reveals its autoinhibition mechanism. Science 341, 172-175.

Hu, Z., Zhou, Q., Zhang, C., Fan, S., Cheng, W., Zhao, Y., Shao, F., Wang, H.W., Sui, S.F., and Chai, J. (2015). Structural and biochemical basis for induced self-propagation of NLRC4. Science 350, 399-404.

Jang, T.H., and Park, H.H. (2014). Crystal structure of TIR domain of TLR6 reveals novel dimeric interface of TIR-TIR interaction for toll-like receptor signaling pathway. Journal of molecular biology 426, 3305-3313.

Jiang, F., Ramanathan, A., Miller, M.T., Tang, G.Q., Gale, M., Jr., Patel, S.S., and Marcotrigiano, J. (2011). Structural basis of RNA recognition and activation by innate immune receptor RIG-I. Nature 479, 423-427.

Jiang, X., Kinch, L.N., Brautigam, C.A., Chen, X., Du, F., Grishin, N.V., and Chen, Z.J. (2012).

Ubiquitin-induced oligomerization of the RNA sensors RIG-I and MDA5 activates antiviral innate immune response. Immunity 36, 959-973.

Jin, T., Perry, A., Jiang, J., Smith, P., Curry, J.A., Unterholzner, L., Jiang, Z., Horvath, G., Rathinam, V.A., Johnstone, R.W., Hornung, V., Latz, E., Bowie, A.G., Fitzgerald, K.A., and Xiao, T.S. (2012). Structures of the HIN domain:DNA complexes reveal ligand binding and activation mechanisms of the AIM2 inflammasome and IFI16 receptor. Immunity 36, 561-571.

Jin, T., Perry, A., Smith, P., Jiang, J., and Xiao, T.S. (2013). Structure of the absent in melanoma 2 (AIM2) pyrin domain provides insights into the mechanisms of AIM2 autoinhibition and inflammasome assembly. The Journal of biological chemistry 288, 13225-13235.

Jones, J.D., and Dangl, J.L. (2006). The plant immune system. Nature 444, 323-329.

Kagan, J.C., and Medzhitov, R. (2006). Phosphoinositide-mediated adaptor recruitment controls Toll-like receptor signaling. Cell 125, 943-955.

Kagan, J.C., Su, T., Horng, T., Chow, A., Akira, S., and Medzhitov, R. (2008). TRAM couples endocytosis of Toll-like receptor 4 to the induction of interferon-beta. Nature immunology 9 , 361-368.

Kato, H., Takeuchi, O., Mikamo-Satoh, E., Hirai, R., Kawai, T., Matsushita, K., Hiiragi, A., Dermody, T.S., Fujita, T., and Akira, S. (2008). Length-dependent recognition of double-stranded ribonucleic acids by retinoic acid-inducible gene-I and melanoma differentiation-associated gene 5 . The Journal of experimental medicine 205, 1601-1610.

Kato, H., Takeuchi, O., Sato, S., Yoneyama, M., Yamamoto, M., Matsui, K., Uematsu, S., Jung, A., Kawai, T., Ishii, K.J., Yamaguchi, O., Otsu, K., Tsujimura, T., Koh, C.S., Reis e Sousa, C., Matsuura, Y., Fujita, T., and Akira, S. (2006). Differential roles of MDA5 and RIG-I helicases in the recognition of RNA viruses. Nature 441, 101-105.

Kawai, T., Takahashi, K., Sato, S., Coban, C., Kumar, H., Kato, H., Ishii, K.J., Takeuchi, O., and Akira, S. (2005). IPS-1, an adaptor triggering RIG-I- and Mda5-mediated type I interferon induction. Nature immunology 6, 981-988. 
Kayagaki, N., Stowe, I.B., Lee, B.L., O'Rourke, K., Anderson, K., Warming, S., Cuellar, T., Haley, B., Roose-Girma, M., Phung, Q.T., Liu, P.S., Lill, J.R., Li, H., Wu, J., Kummerfeld, S., Zhang, J., Lee, W.P., Snipas, S.J., Salvesen, G.S., Morris, L.X., Fitzgerald, L., Zhang, Y., Bertram, E.M., Goodnow, C.C., and Dixit, V.M. (2015). Caspase-11 cleaves gasdermin D for non-canonical inflammasome signalling. Nature 526, 666-671.

Kersse, K., Verspurten, J., Vanden Berghe, T., and Vandenabeele, P. (2011). The death-fold superfamily of homotypic interaction motifs. Trends Biochem Sci 36, 541-552.

Khan, J.A., Brint, E.K., O'Neill, L.A., and Tong, L. (2004). Crystal structure of the Toll/interleukin-1 receptor domain of human IL-1RAPL. The Journal of biological chemistry 279, 31664-31670. Kofoed, E.M., and Vance, R.E. (2011). Innate immune recognition of bacterial ligands by NAIPs determines inflammasome specificity. Nature 477, 592-595.

Koonin, E.V., and Aravind, L. (2000). The NACHT family - a new group of predicted NTPases implicated in apoptosis and MHC transcription activation. Trends Biochem Sci 25, 223-224. Kortmann, J., Brubaker, S.W., and Monack, D.M. (2015). Cutting Edge: Inflammasome Activation in Primary Human Macrophages Is Dependent on Flagellin. Journal of immunology 195, 815-819. Kowalinski, E., Lunardi, T., McCarthy, A.A., Louber, J., Brunel, J., Grigorov, B., Gerlier, D., and Cusack, S. (2011). Structural basis for the activation of innate immune pattern-recognition receptor RIG-I by viral RNA. Cell 147, 423-435.

Lage, S.L., Longo, C., Branco, L.M., da Costa, T.B., Buzzo Cde, L., and Bortoluci, K.R. (2014). Emerging Concepts about NAIP/NLRC4 Inflammasomes. Frontiers in immunology 5, 309. Leipe, D.D., Koonin, E.V., and Aravind, L. (2004). STAND, a class of P-loop NTPases including animal and plant regulators of programmed cell death: multiple, complex domain architectures, unusual phyletic patterns, and evolution by horizontal gene transfer. Journal of molecular biology 343, 1-28.

Li, J., McQuade, T., Siemer, A.B., Napetschnig, J., Moriwaki, K., Hsiao, Y.S., Damko, E., Moquin, D., Walz, T., McDermott, A., Chan, F.K., and Wu, H. (2012). The RIP1/RIP3 necrosome forms a functional amyloid signaling complex required for programmed necrosis. Cell 150, 339-350. Lin, S.C., Lo, Y.C., and Wu, H. (2010). Helical assembly in the MyD88-IRAK4-IRAK2 complex in TLR/IL-1R signalling. Nature 465, 885-890.

Liu, L., Botos, I., Wang, Y., Leonard, J.N., Shiloach, J., Segal, D.M., and Davies, D.R. (2008). Structural basis of Toll-like receptor 3 signaling with double-stranded RNA. Science 320, 379-381.

Loo, Y.M., Fornek, J., Crochet, N., Bajwa, G., Perwitasari, O., Martinez-Sobrido, L., Akira, S., Gill, M.A., Garcia-Sastre, A., Katze, M.G., and Gale, M., Jr. (2008). Distinct RIG-I and MDA5 signaling by RNA viruses in innate immunity. Journal of virology 82, 335-345.

Lu, A., Kabaleeswaran, V., Fu, T., Magupalli, V.G., and Wu, H. (2014a). Crystal structure of the F27G AIM2 PYD mutant and similarities of its self-association to DED/DED interactions. Journal of molecular biology 426, 1420-1427.

Lu, A., Li, Y., Schmidt, F.I., Yin, Q., Chen, S., Fu, T.M., Tong, A.B., Ploegh, H.L., Mao, Y., and Wu, H. (2016). Molecular basis of caspase-1 polymerization and its inhibition by a new capping mechanism. Nature structural \& molecular biology 23, 416-425.

Lu, A., Li, Y., Yin, Q., Ruan, J., Yu, X., Engelman, E., and Wu, H. (2015). Plasticity in PYD assembly revealed by cryo-EM structure of the PYD filament of AIM2. Cell Discovery 1.

Lu, A., Magupalli, V.G., Ruan, J., Yin, Q., Atianand, M.K., Vos, M.R., Schroder, G.F., Fitzgerald, K.A., $\mathrm{Wu}, \mathrm{H}$., and Egelman, E.H. (2014b). Unified polymerization mechanism for the assembly of ASCdependent inflammasomes. Cell 156, 1193-1206.

$\mathrm{Lu}, \mathrm{A}$., and Wu, H. (2015). Structural mechanisms of inflammasome assembly. The FEBS journal $282,435-444$. 
Luo, D., Ding, S.C., Vela, A., Kohlway, A., Lindenbach, B.D., and Pyle, A.M. (2011). Structural insights into RNA recognition by RIG-I. Cell 147, 409-422.

Man, S.M., Tourlomousis, P., Hopkins, L., Monie, T.P., Fitzgerald, K.A., and Bryant, C.E. (2013). Salmonella infection induces recruitment of Caspase- 8 to the inflammasome to modulate IL1 beta production. Journal of immunology 191, 5239-5246.

Mariathasan, S., Newton, K., Monack, D.M., Vucic, D., French, D.M., Lee, W.P., Roose-Girma, M., Erickson, S., and Dixit, V.M. (2004). Differential activation of the inflammasome by caspase-1 adaptors ASC and Ipaf. Nature 430, 213-218.

Martin, B.N., Wang, C., Zhang, C.J., Kang, Z., Gulen, M.F., Zepp, J.A., Zhao, J., Bian, G., Do, J.S., Min, B., Pavicic, P.G., Jr., El-Sanadi, C., Fox, P.L., Akitsu, A., Iwakura, Y., Sarkar, A., Wewers, M.D., Kaiser, W.J., Mocarski, E.S., Rothenberg, M.E., Hise, A.G., Dubyak, G.R., Ransohoff, R.M., and Li, X. (2016). T cell-intrinsic ASC critically promotes TH17-mediated experimental autoimmune encephalomyelitis. Nature immunology 17, 583-592.

Martinon, F., Burns, K., and Tschopp, J. (2002). The inflammasome: a molecular platform triggering activation of inflammatory caspases and processing of proIL-beta. Molecular cell 10, 417-426.

Masumoto, J., Taniguchi, S., and Sagara, J. (2001). Pyrin N-terminal homology domain- and caspase recruitment domain-dependent oligomerization of ASC. Biochem Biophys Res Commun 280, 652-655.

Medzhitov, R., Preston-Hurlburt, P., Kopp, E., Stadlen, A., Chen, C., Ghosh, S., and Janeway, C.A., Jr. (1998). MyD88 is an adaptor protein in the hToll/IL-1 receptor family signaling pathways.

Molecular cell 2, 253-258.

Meylan, E., Curran, J., Hofmann, K., Moradpour, D., Binder, M., Bartenschlager, R., and Tschopp, J. (2005). Cardif is an adaptor protein in the RIG-I antiviral pathway and is targeted by hepatitis C virus. Nature 437, 1167-1172.

Morrone, S.R., Matyszewski, M., Yu, X., Delannoy, M., Egelman, E.H., and Sohn, J. (2015).

Assembly-driven activation of the AIM2 foreign-dsDNA sensor provides a polymerization template for downstream ASC. Nature communications 6, 7827.

Motshwene, P.G., Moncrieffe, M.C., Grossmann, J.G., Kao, C., Ayaluru, M., Sandercock, A.M., Robinson, C.V., Latz, E., and Gay, N.J. (2009). An oligomeric signaling platform formed by the Tolllike receptor signal transducers MyD88 and IRAK-4. The Journal of biological chemistry 284, 25404-25411.

Nimma, S., Ve, T., Williams, S.J., and Kobe, B. (2017). Towards the structure of the TIR-domain signalosome. Current opinion in structural biology.

Nunez Miguel, R., Wong, J., Westoll, J.F., Brooks, H.J., O'Neill, L.A., Gay, N.J., Bryant, C.E., and Monie, T.P. (2007). A dimer of the Toll-like receptor 4 cytoplasmic domain provides a specific scaffold for the recruitment of signalling adaptor proteins. PloS one 2, e788.

Nyman, T., Stenmark, P., Flodin, S., Johansson, I., Hammarstrom, M., and Nordlund, P. (2008). The crystal structure of the human Toll-like receptor 10 cytoplasmic domain reveals a putative signaling dimer. The Journal of biological chemistry 283, 11861-11865.

Ohnishi, H., Tochio, H., Kato, Z., Orii, K.E., Li, A., Kimura, T., Hiroaki, H., Kondo, N., and Shirakawa, M. (2009). Structural basis for the multiple interactions of the MyD88 TIR domain in TLR4 signaling. Proceedings of the National Academy of Sciences of the United States of America 106, 10260-10265.

Oshiumi, H., Matsumoto, M., Funami, K., Akazawa, T., and Seya, T. (2003a). TICAM-1, an adaptor molecule that participates in Toll-like receptor 3-mediated interferon-beta induction. Nature immunology 4, 161-167. 
Oshiumi, H., Sasai, M., Shida, K., Fujita, T., Matsumoto, M., and Seya, T. (2003b). TIR-containing adapter molecule (TICAM)-2, a bridging adapter recruiting to toll-like receptor 4 TICAM-1 that induces interferon-beta. The Journal of biological chemistry 278, 49751-49762.

Osterloh, J.M., Yang, J., Rooney, T.M., Fox, A.N., Adalbert, R., Powell, E.H., Sheehan, A.E., Avery, M.A., Hackett, R., Logan, M.A., MacDonald, J.M., Ziegenfuss, J.S., Milde, S., Hou, Y.J., Nathan, C., Ding, A., Brown, R.H., Jr., Conforti, L., Coleman, M., Tessier-Lavigne, M., Zuchner, S., and Freeman, M.R. (2012). dSarm/Sarm1 is required for activation of an injury-induced axon death pathway. Science 337, 481-484.

Pandey, S., Kawai, T., and Akira, S. (2015). Microbial sensing by Toll-like receptors and intracellular nucleic acid sensors. Cold Spring Harbor perspectives in biology 7, a016246. Panneerselvam, P., and Ding, J.L. (2015). Beyond TLR signaling-the role of SARM in antiviral immune defense, apoptosis \& development. International reviews of immunology 34, 432-444. Park, H.H., Logette, E., Raunser, S., Cuenin, S., Walz, T., Tschopp, J., and Wu, H. (2007). Death domain assembly mechanism revealed by crystal structure of the oligomeric PIDDosome core complex. Cell 128, 533-546.

Patel, J.R., Jain, A., Chou, Y.Y., Baum, A., Ha, T., and Garcia-Sastre, A. (2013). ATPase-driven oligomerization of RIG-I on RNA allows optimal activation of type-I interferon. EMBO reports 14, 780-787.

Peisley, A., Lin, C., Wu, B., Orme-Johnson, M., Liu, M., Walz, T., and Hur, S. (2011). Cooperative assembly and dynamic disassembly of MDA5 filaments for viral dsRNA recognition. Proceedings of the National Academy of Sciences of the United States of America 108, 21010-21015. Peisley, A., Wu, B., Xu, H., Chen, Z.J., and Hur, S. (2014). Structural basis for ubiquitin-mediated antiviral signal activation by RIG-I. Nature 509, 110-114.

Peisley, A., Wu, B., Yao, H., Walz, T., and Hur, S. (2013). RIG-I forms signaling-competent filaments in an ATP-dependent, ubiquitin-independent manner. Molecular cell 51, 573-583.

Pichlmair, A., Schulz, O., Tan, C.P., Naslund, T.I., Liljestrom, P., Weber, F., and Reis e Sousa, C. (2006). RIG-I-mediated antiviral responses to single-stranded RNA bearing 5'-phosphates.

Science 314, 997-1001.

Pierini, R., Juruj, C., Perret, M., Jones, C.L., Mangeot, P., Weiss, D.S., and Henry, T. (2012). AIM2/ASC triggers caspase-8-dependent apoptosis in Francisella-infected caspase-1-deficient macrophages. Cell death and differentiation 19, 1709-1721.

Proell, M., Gerlic, M., Mace, P.D., Reed, J.C., and Riedl, S.J. (2013). The CARD plays a critical role in ASC foci formation and inflammasome signalling. The Biochemical journal 449, 613-621.

Rathinam, V.A., and Fitzgerald, K.A. (2016). Inflammasome complexes: emerging mechanisms and effector functions. Cell 165, 792-800.

Rowe, D.C., McGettrick, A.F., Latz, E., Monks, B.G., Gay, N.J., Yamamoto, M., Akira, S., O'Neill, L.A., Fitzgerald, K.A., and Golenbock, D.T. (2006). The myristoylation of TRIF-related adaptor molecule is essential for Toll-like receptor 4 signal transduction. Proceedings of the National Academy of Sciences of the United States of America 103, 6299-6304.

Sagulenko, V., Thygesen, S.J., Sester, D.P., Idris, A., Cridland, J.A., Vajjhala, P.R., Roberts, T.L., Schroder, K., Vince, J.E., Hill, J.M., Silke, J., and Stacey, K.J. (2013). AIM2 and NLRP3

inflammasomes activate both apoptotic and pyroptotic death pathways via ASC. Cell death and differentiation 20,1149-1160.

Salvesen, G.S., and Walsh, C.M. (2014). Functions of caspase 8: the identified and the mysterious. Seminars in immunology 26, 246-252.

Satoh, T., Kato, H., Kumagai, Y., Yoneyama, M., Sato, S., Matsushita, K., Tsujimura, T., Fujita, T., Akira, S., and Takeuchi, O. (2010). LGP2 is a positive regulator of RIG-I- and MDA5-mediated 
antiviral responses. Proceedings of the National Academy of Sciences of the United States of America 107, 1512-1517.

Saupe, S., Turcq, B., and Begueret, J. (1995). Sequence diversity and unusual variability at the hetc locus involved in vegetative incompatibility in the fungus Podospora anserina. Current genetics $27,466-471$.

Sborgi, L., Ravotti, F., Dandey, V.P., Dick, M.S., Mazur, A., Reckel, S., Chami, M., Scherer, S., Huber, M., Bockmann, A., Egelman, E.H., Stahlberg, H., Broz, P., Meier, B.H., and Hiller, S. (2015).

Structure and assembly of the mouse ASC inflammasome by combined NMR spectroscopy and cryo-electron microscopy. Proceedings of the National Academy of Sciences of the United States of America 112, 13237-13242.

Schmidt, F.I., Lu, A., Chen, J.W., Ruan, J., Tang, C., Wu, H., and Ploegh, H.L. (2016). A single domain antibody fragment that recognizes the adaptor ASC defines the role of ASC domains in inflammasome assembly. The Journal of experimental medicine 213, 771-790.

Schreiber, K.J., Bentham, A., Williams, S.J., Kobe, B., and Staskawicz, B.J. (2016). Multiple domain associations within the Arabidopsis immune receptor RPP1 regulate the activation of programmed cell death. PLoS pathogens 12, e1005769.

Seth, R.B., Sun, L., Ea, C.K., and Chen, Z.J. (2005). Identification and characterization of MAVS, a mitochondrial antiviral signaling protein that activates NF-kappaB and IRF 3. Cell 122, 669-682. Sharma, D., and Kanneganti, T.D. (2016). The cell biology of inflammasomes: Mechanisms of inflammasome activation and regulation. The Journal of cell biology 213, 617-629. Shi, J., Zhao, Y., Wang, K., Shi, X., Wang, Y., Huang, H., Zhuang, Y., Cai, T., Wang, F., and Shao, F. (2015). Cleavage of GSDMD by inflammatory caspases determines pyroptotic cell death. Nature 526, 660-665.

Snyder, G.A., Cirl, C., Jiang, J., Chen, K., Waldhuber, A., Smith, P., Rommler, F., Snyder, N., Fresquez, T., Durr, S., Tjandra, N., Miethke, T., and Xiao, T.S. (2013). Molecular mechanisms for the subversion of MyD88 signaling by TcpC from virulent uropathogenic Escherichia coli.

Proceedings of the National Academy of Sciences of the United States of America 110, 6985-6990. Song, D.H., and Lee, J.O. (2012). Sensing of microbial molecular patterns by Toll-like receptors. Immunol Rev 250, 216-229.

Stylianou, E., O'Neill, L.A., Rawlinson, L., Edbrooke, M.R., Woo, P., and Saklatvala, J. (1992).

Interleukin 1 induces NF-kappa B through its type I but not its type II receptor in lymphocytes. The Journal of biological chemistry 267, 15836-15841.

Tanji, H., Ohto, U., Shibata, T., Miyake, K., and Shimizu, T. (2013). Structural reorganization of the Toll-like receptor 8 dimer induced by agonistic ligands. Science 339, 1426-1429.

Tao, X., Xu, Y., Zheng, Y., Beg, A.A., and Tong, L. (2002). An extensively associated dimer in the structure of the C713S mutant of the TIR domain of human TLR2. Biochem Biophys Res Commun 299, 216-221.

Tenthorey, J.L., Kofoed, E.M., Daugherty, M.D., Malik, H.S., and Vance, R.E. (2014). Molecular basis for specific recognition of bacterial ligands by NAIP/NLRC4 inflammasomes. Molecular cell 54, 17-29.

Ting, J.P., Lovering, R.C., Alnemri, E.S., Bertin, J., Boss, J.M., Davis, B.K., Flavell, R.A., Girardin, S.E., Godzik, A., Harton, J.A., Hoffman, H.M., Hugot, J.P., Inohara, N., Mackenzie, A., Maltais, L.J., Nunez, G., Ogura, Y., Otten, L.A., Philpott, D., Reed, J.C., Reith, W., Schreiber, S., Steimle, V., and Ward, P.A. (2008). The NLR gene family: a standard nomenclature. Immunity 28, 285-287.

Toshchakov, V.Y., Szmacinski, H., Couture, L.A., Lakowicz, J.R., and Vogel, S.N. (2011). Targeting TLR4 signaling by TLR4 Toll/IL-1 receptor domain-derived decoy peptides: identification of the TLR4 Toll/IL-1 receptor domain dimerization interface. Journal of immunology 186, 4819-4827. 
Triantafilou, K., Vakakis, E., Kar, S., Richer, E., Evans, G.L., and Triantafilou, M. (2012).

Visualisation of direct interaction of MDA5 and the dsRNA replicative intermediate form of positive strand RNA viruses. Journal of cell science 125, 4761-4769.

Ullah, M.O., Sweet, M.J., Mansell, A., Kellie, S., and Kobe, B. (2016). TRIF-dependent TLR signaling, its functions in host defense and inflammation, and its potential as a therapeutic target. Journal of leukocyte biology 100, 27-45.

Vajjhala, P.R., Lu, A., Brown, D.L., Pang, S.W., Sagulenko, V., Sester, D.P., Cridland, S.O., Hill, J.M., Schroder, K., Stow, J.L., Wu, H., and Stacey, K.J. (2015). The inflammasome adaptor ASC induces procaspase-8 death effector domain filaments. The Journal of biological chemistry 290, 2921729230.

Vajjhala, P.R., Mirams, R.E., and Hill, J.M. (2012). Multiple binding sites on the pyrin domain of ASC protein allow self-association and interaction with NLRP3 protein. The Journal of biological chemistry 287, 41732-41743.

Valkov, E., Stamp, A., Dimaio, F., Baker, D., Verstak, B., Roversi, P., Kellie, S., Sweet, M.J., Mansell, A., Gay, N.J., Martin, J.L., and Kobe, B. (2011). Crystal structure of Toll-like receptor adaptor MAL/TIRAP reveals the molecular basis for signal transduction and disease protection.

Proceedings of the National Academy of Sciences of the United States of America 108, 1487914884.

van der Biezen, E.A., and Jones, J.D. (1998). The NB-ARC domain: a novel signalling motif shared by plant resistance gene products and regulators of cell death in animals. Current biology : CB 8 , R226-227.

Vazquez, C., and Horner, S.M. (2015). MAVS coordination of antiviral innate immunity. Journal of virology 89, 6974-6977.

Ve, T., Gay, N.J., Mansell, A., Kobe, B., and Kellie, S. (2012). Adaptors in Toll-like receptor signaling and their potential as therapeutic targets. Curr Drug Targets 13,1360-1374.

Ve, T., Williams, S.J., and Kobe, B. (2015). Structure and function of Toll/interleukin-1

receptor/resistance protein (TIR) domains. Apoptosis : an international journal on programmed cell death 20, 250-261.

Venkataraman, T., Valdes, M., Elsby, R., Kakuta, S., Caceres, G., Saijo, S., Iwakura, Y., and Barber, G.N. (2007). Loss of DExD/H box RNA helicase LGP2 manifests disparate antiviral responses. Journal of immunology 178, 6444-6455.

Vyncke, L., Bovijn, C., Pauwels, E., Van Acker, T., Ruyssinck, E., Burg, E., Tavernier, J., and Peelman, F. (2016). Reconstructing the TIR side of the Myddosome: a paradigm for TIR-TIR interactions.

Structure 24, 437-447.

Wesche, H., Henzel, W.J., Shillinglaw, W., Li, S., and Cao, Z. (1997). MyD88: an adapter that recruits IRAK to the IL-1 receptor complex. Immunity 7, 837-847.

Williams, S.J., Sohn, K.H., Wan, L., Bernoux, M., Sarris, P.F., Segonzac, C., Ve, T., Ma, Y., Saucet, S.B., Ericsson, D.J., Casey, L.W., Lonhienne, T., Winzor, D.J., Zhang, X., Coerdt, A., Parker, J.E., Dodds, P.N., Kobe, B., and Jones, J.D. (2014). Structural basis for assembly and function of a heterodimeric plant immune receptor. Science 344, 299-303.

Wu, B., Peisley, A., Richards, C., Yao, H., Zeng, X., Lin, C., Chu, F., Walz, T., and Hur, S. (2013). Structural basis for dsRNA recognition, filament formation, and antiviral signal activation by MDA5. Cell 152, 276-289.

Wu, B., Peisley, A., Tetrault, D., Li, Z., Egelman, E.H., Magor, K.E., Walz, T., Penczek, P.A., and Hur, S. (2014). Molecular imprinting as a signal-activation mechanism of the viral RNA sensor RIG-I. Molecular cell 55, 511-523.

$\mathrm{Wu}, \mathrm{H}$. (2013). Higher-order assemblies in a new paradigm of signal transduction. Cell 153, 287292. 
Xu, H., He, X., Zheng, H., Huang, L.J., Hou, F., Yu, Z., de la Cruz, M.J., Borkowski, B., Zhang, X., Chen, Z.J., and Jiang, Q.X. (2014). Structural basis for the prion-like MAVS filaments in antiviral innate immunity. eLife 3, e01489.

Xu, L.G., Wang, Y.Y., Han, K.J., Li, L.Y., Zhai, Z., and Shu, H.B. (2005). VISA is an adapter protein required for virus-triggered IFN-beta signaling. Molecular cell 19, 727-740.

Xu, Y., Tao, X., Shen, B., Horng, T., Medzhitov, R., Manley, J.L., and Tong, L. (2000). Structural basis for signal transduction by the Toll/interleukin-1 receptor domains. Nature 408, 111-115.

Yamamoto, M., Sato, S., Hemmi, H., Hoshino, K., Kaisho, T., Sanjo, H., Takeuchi, O., Sugiyama, M., Okabe, M., Takeda, K., and Akira, S. (2003). Role of adaptor TRIF in the MyD88-independent tolllike receptor signaling pathway. Science 301, 640-643.

Yamamoto, M., Sato, S., Hemmi, H., Sanjo, H., Uematsu, S., Kaisho, T., Hoshino, K., Takeuchi, O., Kobayashi, M., Fujita, T., Takeda, K., and Akira, S. (2002). Essential role for TIRAP in activation of the signalling cascade shared by TLR2 and TLR4. Nature 420, 324-329.

Yang, J., Zhao, Y., Shi, J., and Shao, F. (2013). Human NAIP and mouse NAIP1 recognize bacterial type III secretion needle protein for inflammasome activation. Proceedings of the National Academy of Sciences of the United States of America 110, 14408-14413.

Yin, Q., Fu, T.M., Li, J., and Wu, H. (2015). Structural biology of innate immunity. Annual review of immunology 33, 393-416.

Yoneyama, M., Kikuchi, M., Natsukawa, T., Shinobu, N., Imaizumi, T., Miyagishi, M., Taira, K., Akira, S., and Fujita, T. (2004). The RNA helicase RIG-I has an essential function in double-stranded RNA-induced innate antiviral responses. Nature immunology 5, 730-737.

Yoon, S.I., Kurnasov, O., Natarajan, V., Hong, M., Gudkov, A.V., Osterman, A.L., and Wilson, I.A. (2012). Structural basis of TLR5-flagellin recognition and signaling. Science 335, 859-864.

Yu, J.W., Wu, J., Zhang, Z., Datta, P., Ibrahimi, I., Taniguchi, S., Sagara, J., Fernandes-Alnemri, T., and Alnemri, E.S. (2006). Cryopyrin and pyrin activate caspase-1, but not NF-kappaB, via ASC oligomerization. Cell death and differentiation 13, 236-249.

Zeng, W., Sun, L., Jiang, X., Chen, X., Hou, F., Adhikari, A., Xu, M., and Chen, Z.J. (2010).

Reconstitution of the RIG-I pathway reveals a signaling role of unanchored polyubiquitin chains in innate immunity. Cell 141, 315-330.

Zhang, L., Chen, S., Ruan, J., Wu, J., Tong, A.B., Yin, Q., Li, Y., David, L., Lu, A., Wang, W.L., Marks, C., Ouyang, Q., Zhang, X., Mao, Y., and Wu, H. (2015). Cryo-EM structure of the activated NAIP2NLRC4 inflammasome reveals nucleated polymerization. Science 350, 404-409.

Zhang, Z., Ohto, U., Shibata, T., Krayukhina, E., Taoka, M., Yamauchi, Y., Tanji, H., Isobe, T., Uchiyama, S., Miyake, K., and Shimizu, T. (2016). Structural analysis reveals that Toll-like receptor 7 Is a dual receptor for guanosine and single-stranded RNA. Immunity 45, 737-748. Zhao, Y., Yang, J., Shi, J., Gong, Y.N., Lu, Q., Xu, H., Liu, L., and Shao, F. (2011). The NLRC4 inflammasome receptors for bacterial flagellin and type III secretion apparatus. Nature 477, 596600. 
PRR

Activation and oligomerization of PRR

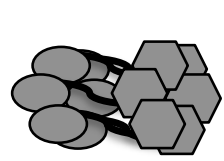

Recruitment of ASC and nucleation of ASC filament
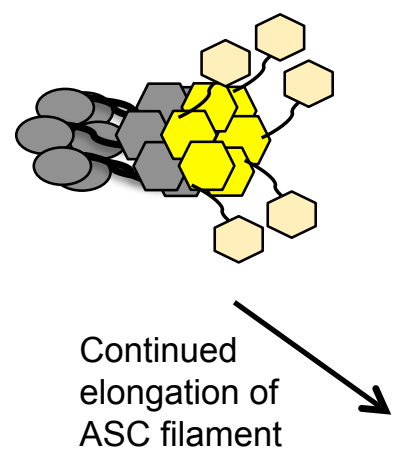

Proximity-induced dimerization and activation of procaspases- 1 and -8

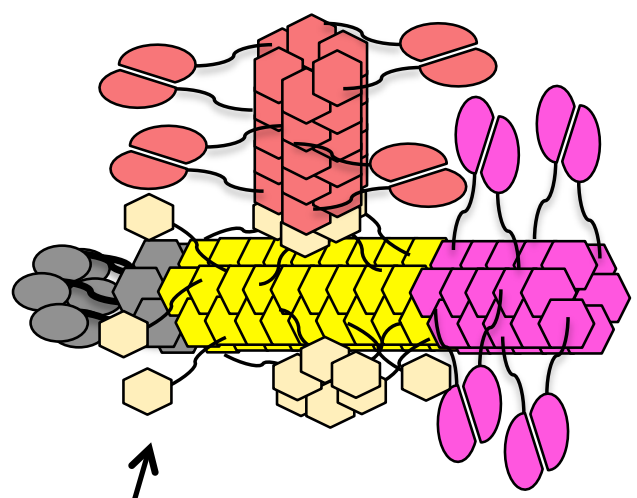

Recruitment and nucleation of filaments of procaspases- 1 and -8

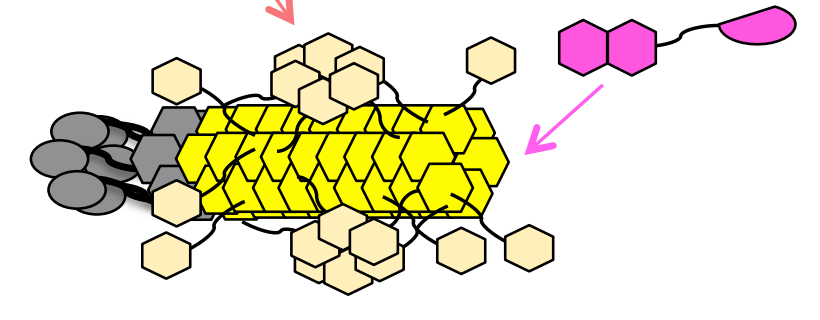



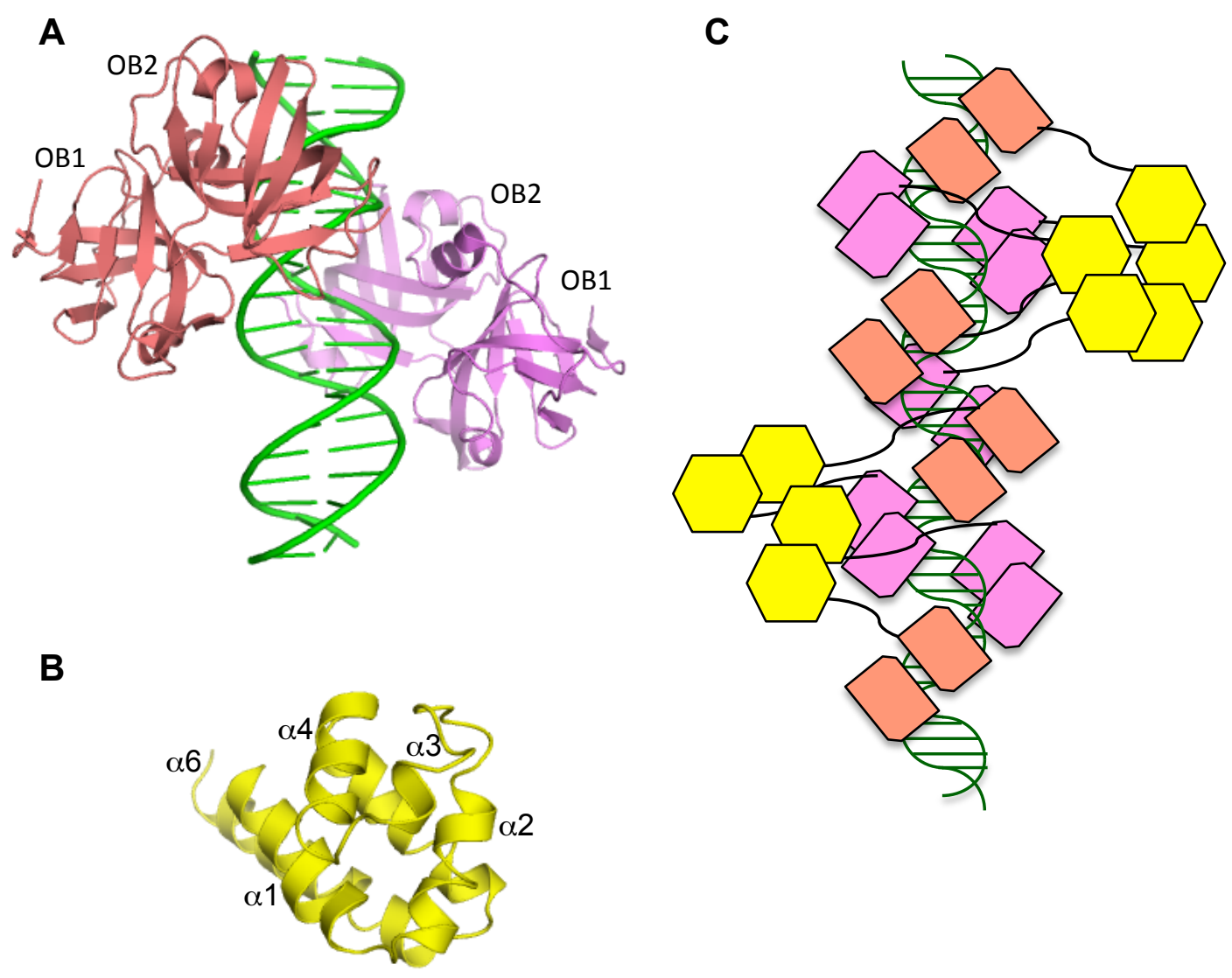

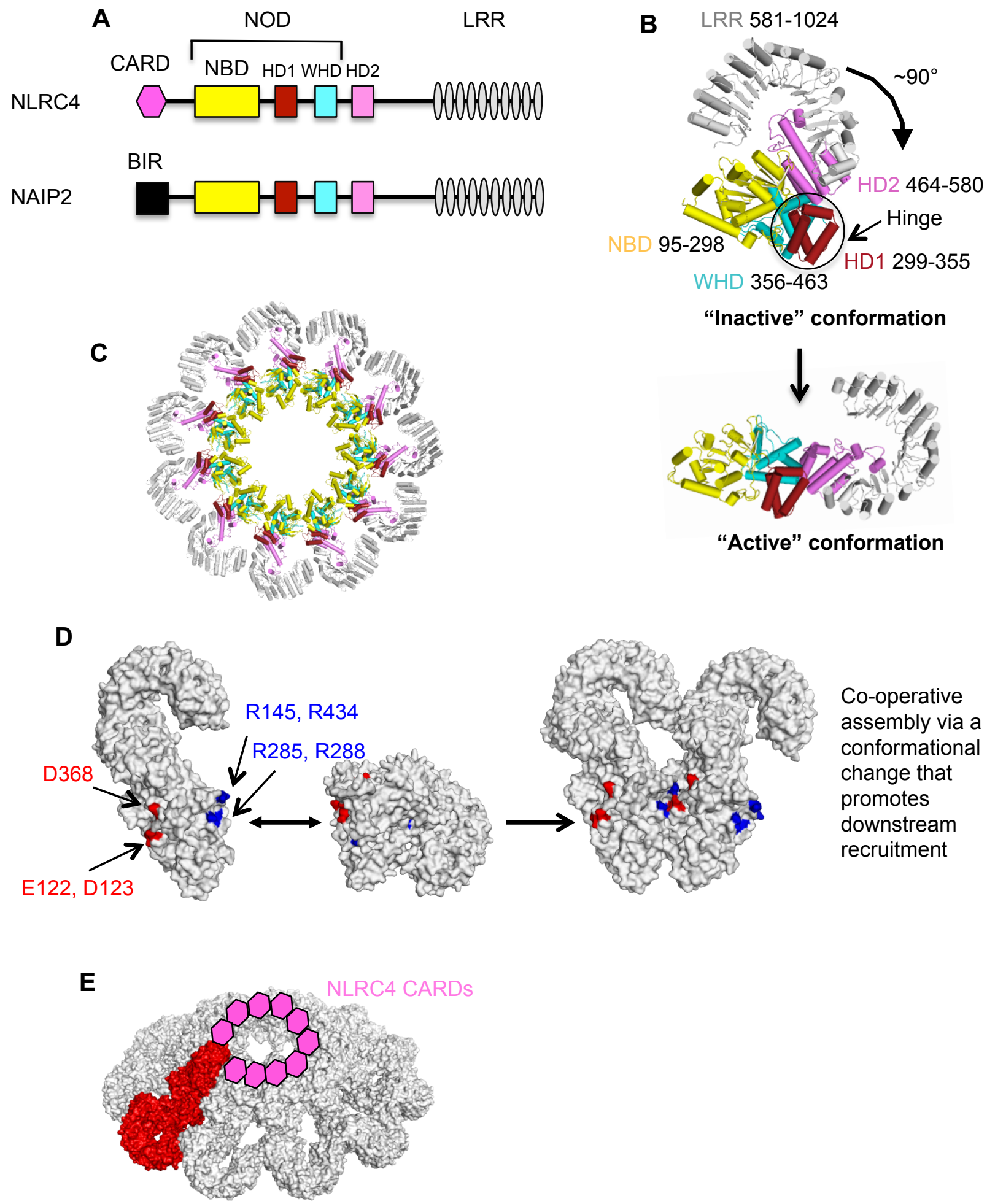
A

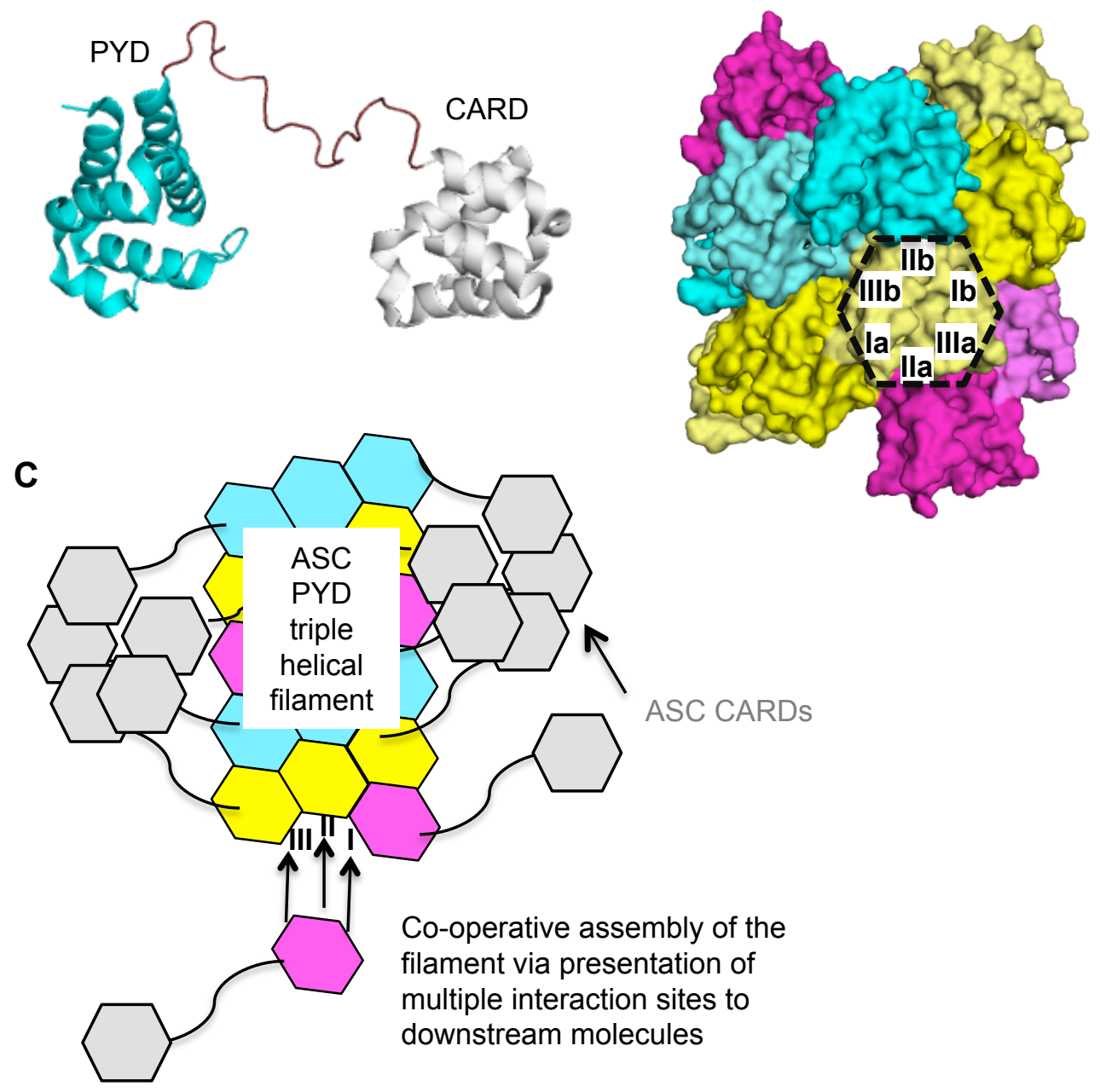

B 


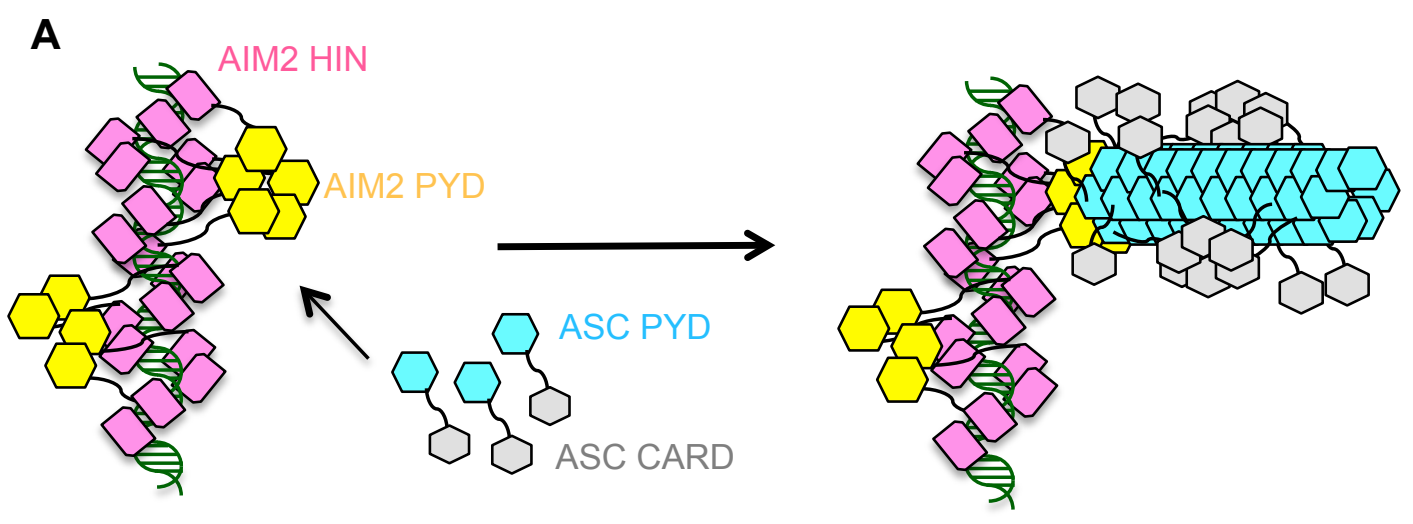

B

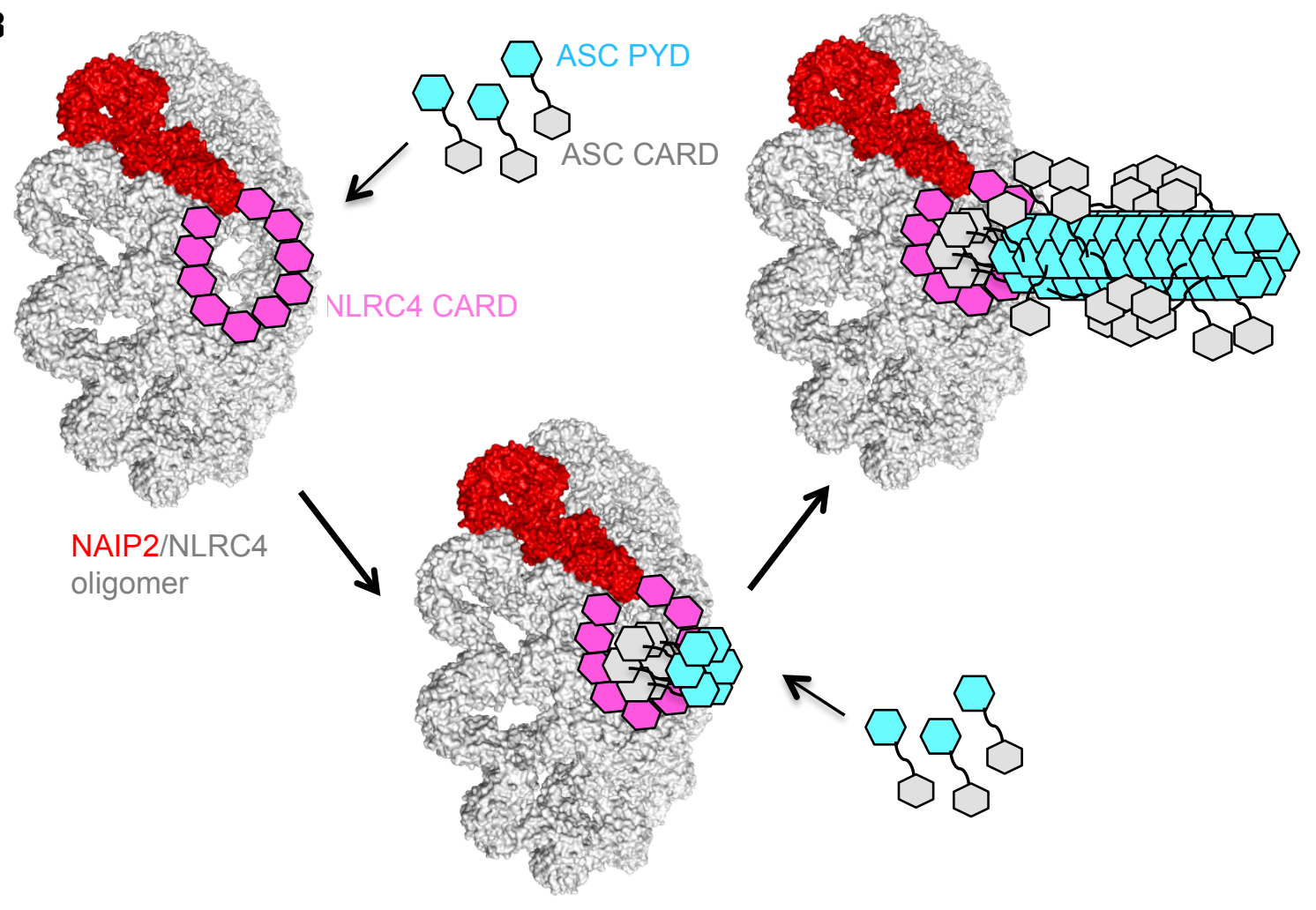




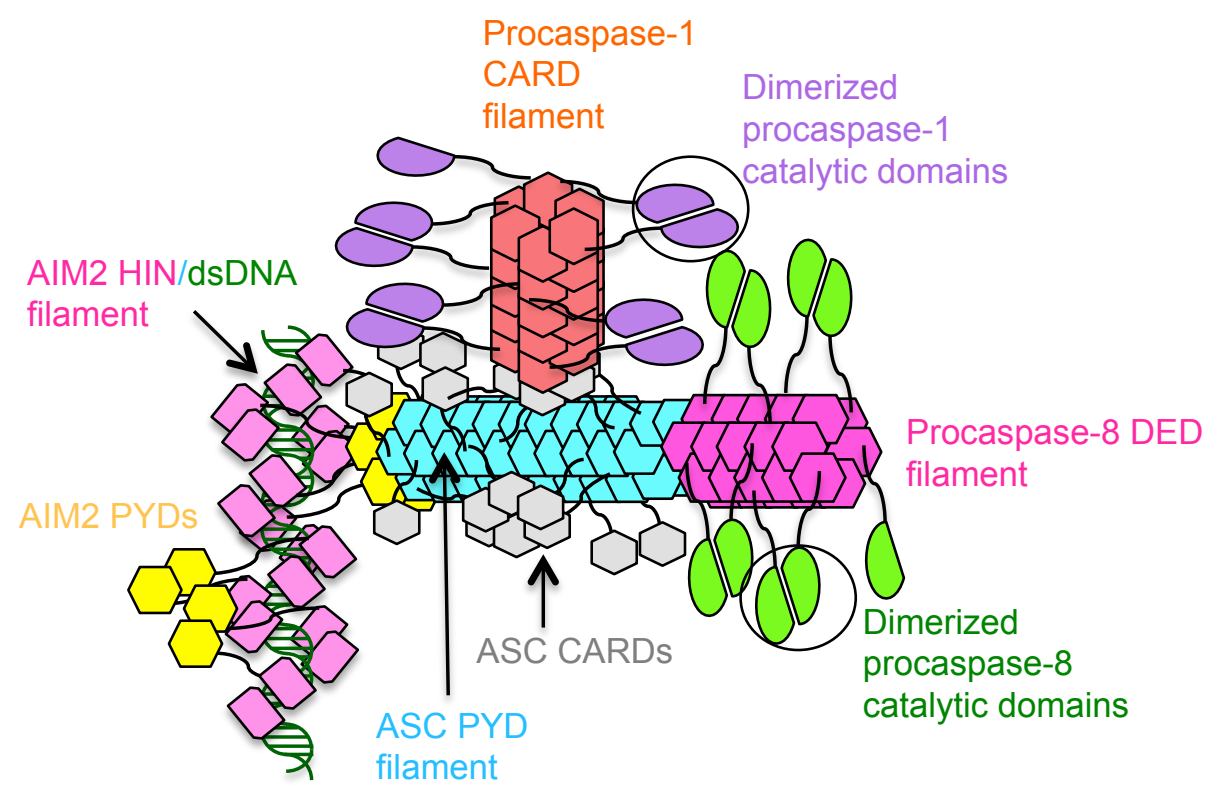


RIG-I/MDA5 ON dsRNA

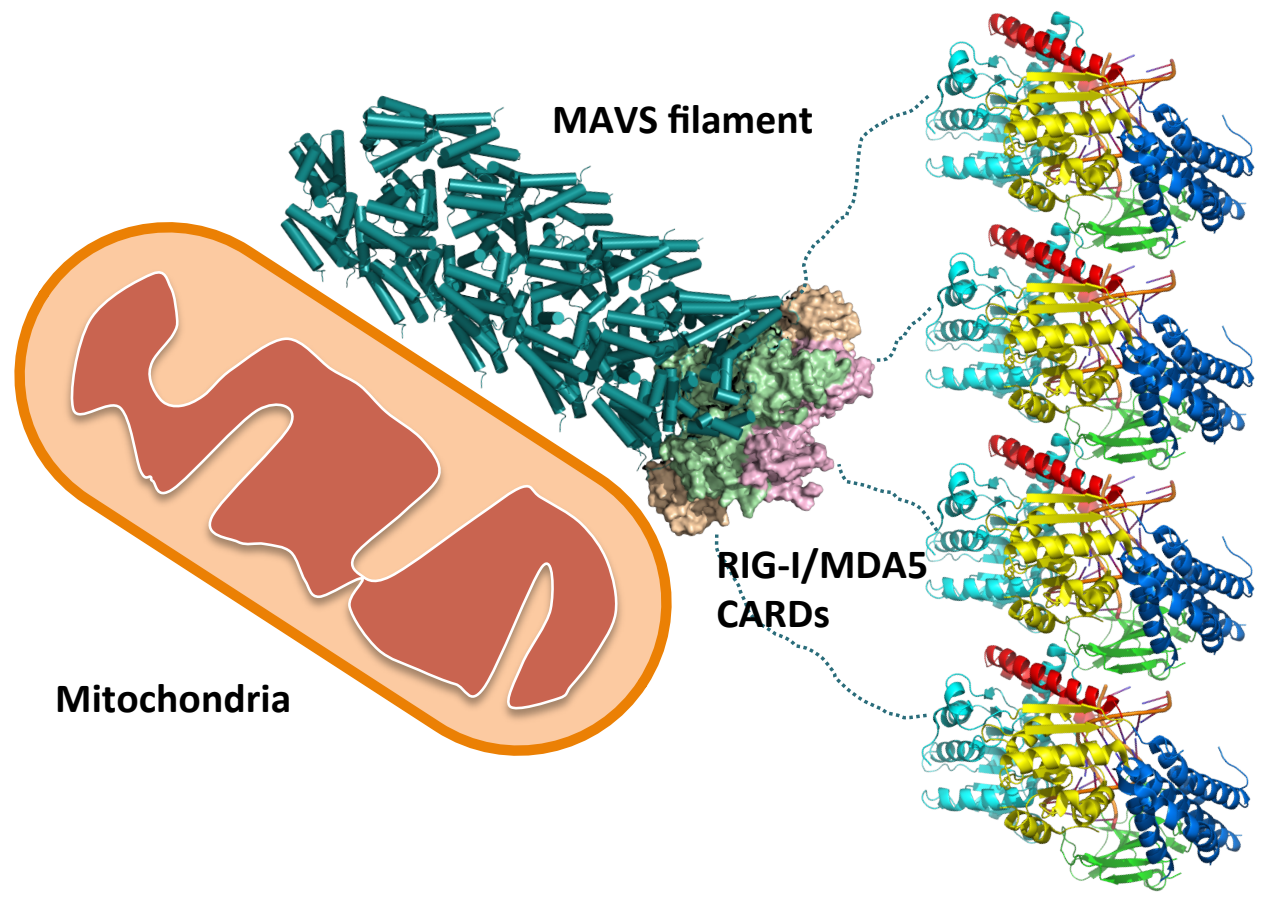




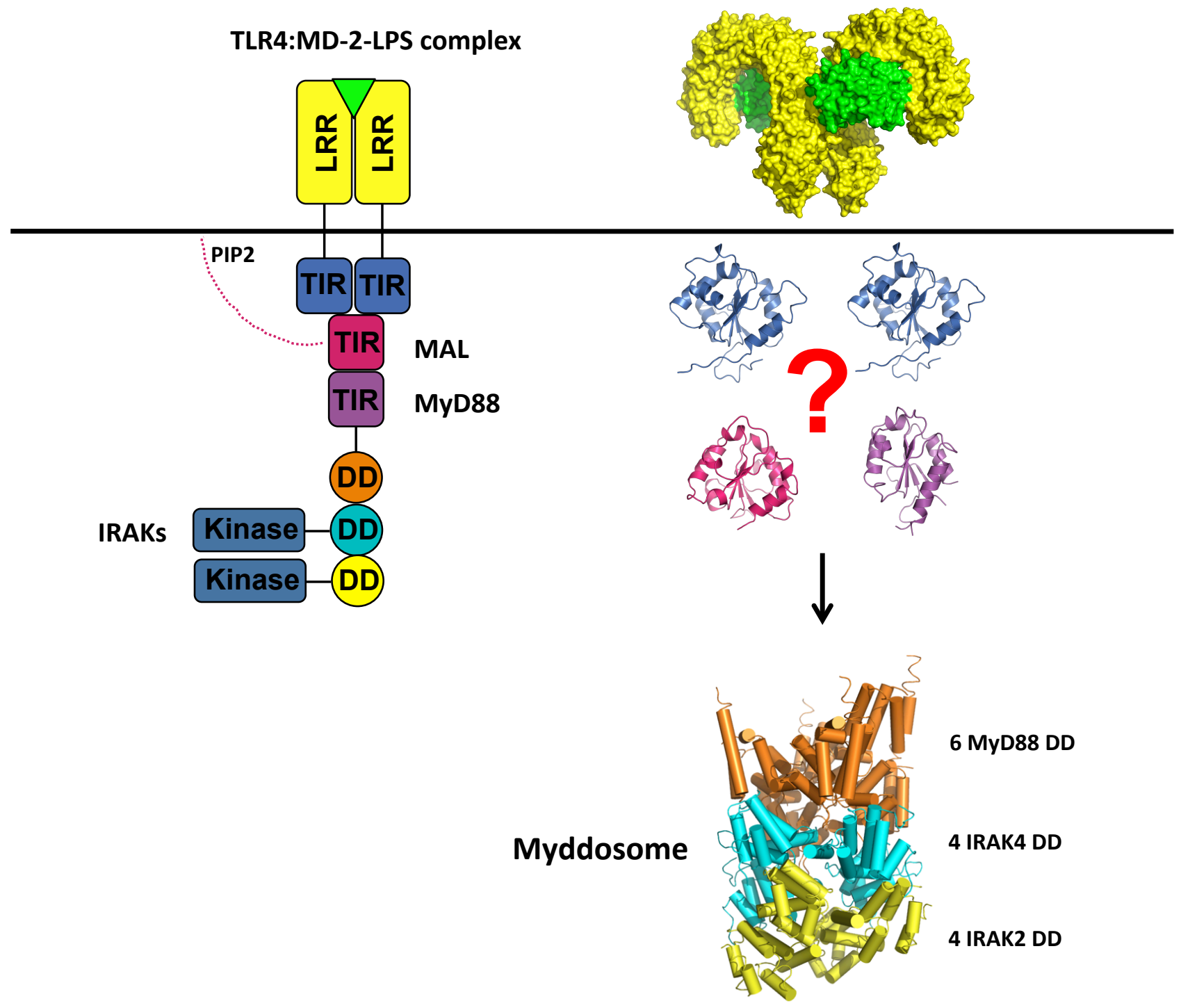

